\title{
Alergenos: relación entre función biológica y alergenicidad
}

\author{
Homero San Juan, Leonardo Puerta, Luis Caraballo
}

\begin{abstract}
Resumen
Los alergenos se encuentran en muy diversas fuentes, pero, tienen la particularidad de inducir la producción de inmunoglobulina $\mathrm{E}(\mathrm{lgE})$ y provocar alergia. No se conoce una característica molecular biológica común entre los alergenos que explique su capacidad alergénica. En los últimos años, se han demostrado o inferido diferentes funciones biológicas en los alergenos, generando nuevas hipótesis sobre el papel de dichas funciones en la actividad alergénica. Con el fin de identificar qué funciones biológicas se han demostrado o inferido en los alergenos y analizar su posible influencia en el papel alergénico, se revisaron aproximadamente doscientos alergenos teniendo como base los ya caracterizados por el Comité de Nomenclatura de Alergenos de la OMS, como también otros menos caracterizados pero con algunas propiedades fisicogituímicas conocidas. Los alergenos se agruparon de acuerdo con la actividad biológica y se tabularon con su fuente de origen, peso molecular (PM), punto isoeléctrico ( $\mathrm{pl}$ ), frecuencia de reactividad en la población alérgica, potenciales sitios de glicosilación y formación de enlaces disulfuro. Se identificaron 88 alergenos en los que se ha informado alguna actividad biológica. El agrupamiento de estos según la actividad produjo los siguientes resultados: enzimática $(47,2 \%)$, inhibición de enzimas $(11,3 \%)$, transporte $(18,1 \%)$, regulación de la actividad celular $(15,9 \%)$ y otras actividades como la de conferir resistencia a enfermedades en plantas y citólisis (7,9\%). En muchos de estos alergenos, la actividad biológica ha sido inferida por su homología estructural con proteínas de función conocida, pero los experimentos que corroboren dicha función no se han realizado. La mayoría de estos alergenos tienen en común $\mathrm{PM}<60 \mathrm{kDa}, \mathrm{pl}<7,0$ y escasa formación de oligómeros. Nuestro análisis sugiere que la capacidad de inducir alergia no está determinada por ninguna de las funciones biológicas descritas. Aunque la actividad de cisteína-proteasa y serina-proteasa de algunos de los alergenos de los ácaros domésticos han sido señaladas como determinantes en el papel alergénico en dichos alergenos, los datos experimentales no son concluyentes y no permiten atribuir la alergenicidad a la función enzimática.
\end{abstract}

\begin{abstract}
Allergens: the relationship between biological function and allergenicity
Allergens can be found from many diverse sources but they have the particular quality of being able to induce immunoglobulin $E$ ( $\mathrm{IgE}$ ) production and to provoke allergy. $A$ common biological molecular characteristic which can explain their allergenic capacity is not known amongst the allergens. In the last few years allergens' different biological functions have been demonstrated or inferred, generating a new hypothesis about the role of the said functions in allergenic activity. To identify which biological functions have
\end{abstract}

Instituto de Investigaciones Inmunológicas, Universidad de Cartagena

Recibido para su publicación: enero 15 de 1998. 
been demonstrated or inferred in the allergens and to analyse their possible influence on allergenic role, approximately two hundred allergens were revised using those already classified by the WHO's Allergen Nomenclature committee as the basis for characterisation, as were others less characterised, but having some known physicochemical properties. The allergens were grouped according to biological activity and were tabulated with their source of origin, molecular weight (MW), isoelectric point (Ip), reactivity frequency in the allergic population, potential glycosilation and disulphur formation of enlacing sites. Eighty-eight allergens were identified amongst those in which some biological activity had been reported. The grouping of these according to activity produced the following results: enzymatic $(47,2 \%)$, enzyme inhibition $(11,3 \%)$, transport $(18,1 \%)$, cellular activity regulation $(15,9 \%)$ and other activities such as conferring resistance to disease on plants and cytolysis (7,9\%). In many of these allergens, biological activity has been inferred by their structural homology with known function proteins but the experiments which corroborate the said function have not been carried out. The majority of these allergens have a $\mathrm{MW}<60 \mathrm{kDa}, \mathrm{Ip}<7.0$ and scant olygomer formation in common. Analysis suggested that the capacity to induce allergy is not determined by any of the described biological functions. Even though the cysteinprotease and serin-protease activity of some domestic mites' allergens has been pointed out as being determinant in the said allergens' allergenic role, experimental data is not conclusive and does not allow allergenicity to be attributed to an enzymatic function.

Los alergenos son moléculas que provienen de muy diversas fuentes (animal o vegetal) y tienen la particularidad de unirse a la inmunoglobulina E (IgE) y provocar alergias. En su fuente de origen, los alergenos tienen variadas funciones que incluyen actividad enzimática, de transporte, etc., aunque en muchos casos esta función biológica se desconoce, dando la falsa impresión de que su única actividad es la alergenicidad.

Las propiedades alergénicas se han estudiado extensamente; sin embargo, no se ha encontrado una característica molecular común o alguna función específica compartida por los alergenos, que explique su capacidad de inducir alergias.

En los últimos años han aumentado los descubrimientos sobre las funciones biológicas de los alergenos, lo cual ha llevado al interrogante de si alguna de estas funciones pudiera influir en su potencial alergénico. En esta revisión analizamos qué funciones biológicas se han demostrado o sugerido en los alergenos más conocidos y la probable relación de dichas funciones con la alergenicidad.
Se revisaron los alergenos a los cuales se les ha demostrado experimentalmente o inferido por su homología molecular con otras proteínas de función conocida, alguna función biológica. Para esto, consultamos las bases de datos de secuencias de nucleótidos y de aminoácidos (GeneBank y Swiss Prot), MEDLINE (PubMed, on line), los resultados de los tres talleres internacionales sobre alergenos ambientales y asma efectuados hasta el momento, los informes del Comité de Nomenclatura de Alergenos de la OMS, artículos científicos y resúmenes de congresos internacionales.

Para nombrar a los alergenos, seguimos la nomenclatura recomendada por la OMS (1). La información fisicoquímica de cada alergeno, como peso molecular (PM), punto isoeléctrico (pl) y enlace disulfuro se registró para analizar las posibles características moleculares comunes. A aquellos alergenos con epítopes conocidos, se les analizó la naturaleza de éstos y su ubicación en la molécula para establecer si los epítopes B o los epítopes $\mathrm{T}$ hacen parte de la región comprometida con la función biológica de la molécula. 
Se identificaron 88 alergenos a los cuales se les ha demostrado experimentalmente o sugerido alguna función biológica. Dado que ciertos alergenos de diferentes fuentes pueden tener la misma función biológica y para facilitar la presentación de los resultados, los alergenos se agruparon por funciones biológicas así: actividad enzimática (proteasas, carbohidrasas, lipasas, ribonucleasas, oxidoreductasas y transferasas);inhibidores de enzimas (inhibidores de tripsina, de $\alpha$-amilasa y de cisteínaproteasa); función transportadora (hemoglobinas, citocromo $\mathrm{C}$, transportadores de lípidos y ácidos grasos); proteínas reguladoras (los que se unen a la actina, los que se unen al calcio, proteínas de choque térmico); homólogos a la fosfoproteína ácida ribosomal P2, y otras funciones biológicas (proteínas que confieren resistencia a las enfermedades en las plantas, lectinas, proteínas con actividad citolítica). La actividad biológica más frecuente fue la enzimática, la cual se encontró en 42 alergenos; la actividad enzimática más común fue la de proteasa, con especificidades de cisteína-proteasa, serina-proteasa y aspartato- proteasa. Aunque la actividad de cisteínaproteasa y serina-proteasa de los alergenos de los ácaros domésticos han sido señaladas como influyentes en el papel alergénico en dichos alergenos, los datos experimentales no son concluyentes y no permiten atribuir la alergenicidad a la función enzimática.

\section{Alergenos y actividad enzimática}

Encontramos seis actividades enzimáticas (proteasa, carbohidrasa, lipasa, ribonucleasa, oxirreductasa y transferasa) asociadas con alergenos provenientes de los ácaros domésti$\mathrm{cos}$, insectos, polenes, alimentos y hongos (cuadro $1 \mathrm{~A}$ y $1 \mathrm{~B}$ ).

\section{Actividad de proteasa}

Con esta actividad se identificaron varios alergenos con especificidades de cisteínaproteasa, serina-proteasa y aspartato-proteasa.

\section{Cisteína- proteasas}

A los alergenos del grupo 1 de los ácaros domésticos Der $p 1$, Der $f 1$ y Eur $m 1$ se les ha demostrado actividad de cisteína proteasa. Por otro lado, a proteínas de reconocidad actividad

Cuadro 1A. Alergenos y actividad enzimática

\begin{tabular}{|c|c|c|c|c|c|c|c|c|c|}
\hline FUNCION & ALERGENO & FUENTE & \begin{tabular}{|c|} 
FRECUENCIA DE \\
REACTIVIDAD
\end{tabular} & $\begin{array}{l}\text { P.M. } \\
\text { (kDa) }\end{array}$ & $\mathrm{pl}$ & \begin{tabular}{|c|} 
SITIOS DE \\
GLICOSILACION \\
\end{tabular} & $\begin{array}{l}\text { ENLACES } \\
\text { DISULFURO }\end{array}$ & $\begin{array}{c}\text { ACTIVIDAD } \\
\text { ASIGNADA POR }\end{array}$ & REFERENCIAS \\
\hline $\begin{array}{l}\text { CISTEINA- } \\
\text { PROTEASA }\end{array}$ & $\begin{array}{c}\text { Der } \mathrm{p} 1 \\
\text { Der } \mathrm{f} 1 \\
\text { Eur m } 1 \\
\begin{array}{c}\text { Papaina } \\
\text { Bromelaina }\end{array}\end{array}$ & $\begin{array}{l}\text { D. pteronyssinus } \\
\text { D. farinae } \\
\text { E. maynei } \\
\text { Carica papaya } \\
\text { Ananas comosus }\end{array}$ & $\begin{array}{l}90 \% \\
80 \% \\
80 \% \\
-\end{array}$ & $\begin{array}{l}25 \\
25 \\
25 \\
23 \\
23\end{array}$ & $\begin{array}{c}5,7 \\
5,7 \\
4,7-5,4\end{array}$ & $\begin{array}{l}\text { Si (1) } \\
\text { Si (1) } \\
\text { Si (1) } \\
\text { No } \\
\text { Si }\end{array}$ & $\begin{array}{l}\mathrm{Si}(3) \\
\mathrm{Si}(3) \\
\mathrm{Si}(3)\end{array}$ & $\begin{array}{l}\text { Actividad enzimática e identidad } \\
\text { con papaina } \\
\text { Act. enzimática e identidad } \\
\text { con papaina } \\
\text { Act. enzimática e identidad } \\
\text { con Der p } 1 \\
\text { Actividad enzimática } \\
\text { Actividad enzimática }\end{array}$ & $\begin{array}{c}2,5,11,12 \\
3,5 \\
4,5 \\
25 \\
45\end{array}$ \\
\hline $\begin{array}{l}\text { SERINA- } \\
\text { PROTEASA }\end{array}$ & $\begin{array}{c}\text { Der } p 3 \\
\text { Der p6 } \\
\text { Der p } 9 \\
\text { Der } \mathrm{f3} \\
\text { Der f6 } \\
\\
\text { Tripsina } \\
\text { Quimotripsina } \\
\text { Subtilisinas }\end{array}$ & $\begin{array}{l}\text { D. pteronyssinus } \\
\text { D. pteronyssinus } \\
\text { D. pteronyssinus } \\
\text { D. farinae } \\
\text { D. farinae } \\
\text { Páncreas porcino } \\
\text { Páncreas bovino } \\
\text { Bacillus subtilis }\end{array}$ & $\begin{array}{c}16-90 \% \\
41-60 \% \\
90 \% \\
42-70 \% \\
31 \% \\
: \\
:\end{array}$ & $\begin{array}{c}24,98 \\
24,9 \\
28 \\
25,27 \\
30 \\
24 \\
25 \\
28\end{array}$ & $\begin{array}{c}4 \\
3,8-4,4 \\
4,8 \text { y } 10,5 \\
4,8\end{array}$ & $\begin{array}{l}\text { No } \\
\text { No } \\
\text { No }\end{array}$ & $\begin{array}{l}\mathrm{Si}(3) \\
\mathrm{Si}(3) \\
\mathrm{Si}(3)\end{array}$ & $\begin{array}{l}\text { Actividad de tripsina e identidad } \\
\text { con serina-proteasas } \\
\text { Actividad de quimotripsina } \\
\text { Actividad de colagenasa } \\
\text { Actividad de tripsina } \\
\text { Actividad de quimotripsina } \\
\text { identidad } \\
\text { N-terminal con quimotripsina }\end{array}$ & $\begin{array}{c}30,33,35 \\
34,35 \\
35,36 \\
31,32,35 \\
35 \\
28 \\
45 \\
29\end{array}$ \\
\hline $\begin{array}{l}\text { ASPARTATO- } \\
\text { PROTEASA }\end{array}$ & $\begin{array}{c}\text { Bla g 2 } \\
\text { Proteasa acida } \\
\text { Pepsina }\end{array}$ & $\begin{array}{l}\text { Blatefia germanica } \\
\text { Candida albicans } \\
\quad \text { Porcino }\end{array}$ & $\begin{array}{l}60 \% \\
45 \% \\
-\end{array}$ & $\begin{array}{c}35,93 \\
44 \\
35\end{array}$ & $\begin{array}{l}5,2 \\
4,2\end{array}$ & No & & $\begin{array}{l}\text { Identidad con pepsina y renina } \\
\text { humana } \\
\text { Actividad aspartato-proteasa } \\
\text { Actividad aspartato-proteasa }\end{array}$ & $\begin{array}{c}40,42 \\
43,44 \\
45\end{array}$ \\
\hline AMILASA & $\begin{array}{l}\text { Asp o } 2 \\
\text { Der p } 4 \\
\alpha \text {-amilasa } \\
\beta \text {-amilasa }\end{array}$ & $\begin{array}{l}\text { Aspergilius oryzae } \\
\text { D. pteronyssinus } \\
\text { Hordeum vulgare } \\
\text { Hordeum vulgare }\end{array}$ & $\begin{array}{c}28.6-56 \% \\
25-46 \% \\
>96 \% \\
>96 \%\end{array}$ & $\begin{array}{l}53 \\
56 \\
64 \\
60\end{array}$ & $\begin{array}{c}4,3 \\
4,9-7,1\end{array}$ & & $\begin{array}{l}\text { Si (4) } \\
\text { Si }\end{array}$ & $\begin{array}{l}\text { Actividad enzimática } \\
\text { Actividad enzimática } \\
\text { Actividad enzimática } \\
\text { Actividad enzimática }\end{array}$ & $\begin{array}{l}46 \cdot 48 \\
53,55 \\
45,50 \\
45,50\end{array}$ \\
\hline HIALURONIDASA & $\begin{array}{l}\text { Api m } 2 \\
\text { Dol } m 2 \\
\text { Ves } m 2\end{array}$ & $\begin{array}{l}\text { Apis mellifera } \\
\text { D. maculata } \\
\text { V. maculifrons }\end{array}$ & : & $\begin{array}{l}43 \\
44 \\
44\end{array}$ & & $\begin{array}{l}\operatorname{Si}(3) \\
\operatorname{Si}(1) \\
\operatorname{Si}(1)\end{array}$ & $\begin{array}{l}\text { Si }(2) \\
\text { Si }(2) \\
\text { Si }(2)\end{array}$ & $\begin{array}{l}\text { Actividad enzimática e identidad } \\
\text { con hialuronidasas como } \mathrm{PH}-20\end{array}$ & $\begin{array}{l}57 \\
56 \\
58\end{array}$ \\
\hline PECTINASA & $\operatorname{Cryj} 2$ & Cryptomeria japonica & $71 \%$ & 42 & 9,5 & Si (3) & & $\begin{array}{l}\begin{array}{l}\text { Actividad enzimática contra } \\
\text { poligalacturonato metilesteri- } \\
\text { ficado }\end{array} \\
\end{array}$ & 59.61 \\
\hline
\end{tabular}


Cuadro 1B. Alergenos y actividad enzimática

\begin{tabular}{|c|c|c|c|c|c|c|c|c|c|}
\hline FUNCION & ALERGENO & FUENTE & \begin{tabular}{|c|} 
FRECUENCIA \\
DE REACTIVIDAD
\end{tabular} & P.M. (kDa) & $\mathrm{pl}$ & \begin{tabular}{|c|} 
SITIOS DE \\
GLICOSILACION \\
\end{tabular} & $\begin{array}{c}\text { ENLACES } \\
\text { DISULFURO } \\
\end{array}$ & $\begin{array}{c}\text { ACTIVIDAD } \\
\text { ASIGNADA POR }\end{array}$ & REFERENCIAS \\
\hline LISOZIMA & $\begin{array}{c}\text { Gal d } 4 \\
\text { Hevamina }\end{array}$ & $\begin{array}{l}\text { Gallus domesticus } \\
\text { Hevea brasiffensis }\end{array}$ & $\begin{array}{l}100 \% \\
3.45 \%\end{array}$ & $\begin{array}{c}14,3 \\
30\end{array}$ & 10,2 & Nó & Si (4) & $\begin{array}{l}\text { Actividad enzimática } \\
\text { Act. enzimática de qutinasa y } \\
\text { lisozima }\end{array}$ & $\begin{array}{l}64 \\
65\end{array}$ \\
\hline FOSFOLIPASA A1B & $\begin{array}{l}\text { Dol m } 1 \\
\text { Ves m } 1\end{array}$ & $\begin{array}{c}\text { D. maculate } \\
\text { Vespula maculifrons }\end{array}$ & . & $\begin{array}{l}34 \\
34\end{array}$ & $8,67-8,9$ & $\begin{array}{c}\text { Si (1) en Dol m } 1.01 \\
\text { No }\end{array}$ & $\begin{array}{l}\text { Si } \\
\text { si }\end{array}$ & $\begin{array}{l}\text { Actividad enzimática } \\
\text { Actividad enzimática }\end{array}$ & $\begin{array}{l}66 \\
66\end{array}$ \\
\hline FOSFOLIPASA A2 & Api $m 1$ & Apis mellifera & - & 16 & & sil(1) & Si( 5$)$ & Actividad enzimática & 68 \\
\hline RIBONUCLEASAS & $\begin{array}{l}\text { Asp f } 1 \\
\text { Phi p } 5 \\
\text { Lol p } 5\end{array}$ & $\begin{array}{l}\text { Aspergillus fumigatus } \\
\text { Phleum pratense } \\
\text { Lolium perenne }\end{array}$ & $\begin{array}{l}20 \% \\
80 \% \\
80 \%\end{array}$ & $\begin{array}{c}18 \\
38(\mathrm{Va}), 32(\mathrm{Vb}) \\
29-31\end{array}$ & $\begin{array}{c}9,3 \\
8,8-9,3 \\
6,0-10,0\end{array}$ & $\begin{array}{l}\text { No } \\
\text { No } \\
\text { No }\end{array}$ & $\begin{array}{l}\text { Sil } 2) \\
\text { No } \\
\text { No }\end{array}$ & $\begin{array}{l}\text { Actividad tipo mitogilina } \\
\text { Actividad RNasa } \\
\text { Identidad con PhI p } 5\end{array}$ & $\begin{array}{c}71,73,74 \\
76,77 \\
45,76\end{array}$ \\
\hline $\begin{array}{l}\text { ALCOHOL } \\
\text { DESHIDROGENASA }\end{array}$ & $\begin{array}{l}\text { Cand a } 1 \\
\text { ADH-1 }\end{array}$ & $\begin{array}{l}\text { Candida albicans } \\
\text { S. cerevisiae }\end{array}$ & . & $\begin{array}{l}40 \\
40\end{array}$ & 6.2 & & $\begin{array}{l}\text { No } \\
\text { No }\end{array}$ & $\begin{array}{l}\text { Identidad con ADH } \\
\text { de S. cerevisiae } \\
\text { Actividad enzimática }\end{array}$ & $\begin{array}{c}78 \\
45,78\end{array}$ \\
\hline $\begin{array}{l}\text { ALDEHIDO } \\
\text { DESHIDROGENASA }\end{array}$ & $\begin{array}{l}\text { Alt a } 10 \\
\mathrm{Clah} 3\end{array}$ & $\begin{array}{l}\text { Aiternaria alternata } \\
\text { C. herbarum }\end{array}$ & $\begin{array}{l}2 \% \\
36 \%\end{array}$ & $\begin{array}{l}53 \\
53\end{array}$ & & $\begin{array}{l}\text { No } \\
\text { No }\end{array}$ & $\begin{array}{l}\text { No } \\
\text { No }\end{array}$ & $\begin{array}{l}\text { Identidad con ALDH } \\
\text { de S. cerevisiae }\end{array}$ & $\begin{array}{l}79 \\
79\end{array}$ \\
\hline PECTATO LIASAS & Cryj 1 & Cryptomeria japonica & $90 \%$ & 38,5 & $8.9 \cdot 9.2$ & si(2) & & $\begin{array}{l}\text { Act. enzimática contra } \\
\text { pectina, identidad con } \\
\text { pectato-liasas de Erwinia }\end{array}$ & 80,81 \\
\hline ENOLASAS & - & $\begin{array}{l}\text { Candida albicans } \\
\text { S. cerevisiae } \\
\text { C. herbarum }\end{array}$ & $\begin{array}{c}37 \% \\
39-68 \% \\
20 \%\end{array}$ & $\begin{array}{l}46 \\
48 \\
47\end{array}$ & $\begin{array}{l}5,4 \\
6,2\end{array}$ & $\begin{array}{l}\text { No } \\
\text { No } \\
\text { No }\end{array}$ & $\begin{array}{l}\text { No } \\
\text { No } \\
\text { No }\end{array}$ & $\begin{array}{l}\text { Actividad enzimática e } \\
\text { identidad con la enolasa de } \\
\text { S. cerevisiae } \\
\text { Actividad enziniática } \\
\text { Identidad con la enolasa de } \\
\text { S. cerevisiae }\end{array}$ & $\begin{array}{c}83,87 \\
84,89 \\
79\end{array}$ \\
\hline \multirow[t]{2}{*}{$\begin{array}{l}\text { GLUTATION-S. } \\
\text { TRANSFERASA }\end{array}$} & Bla g 5 & Blatefla germanica & $70 \%$ & 25 & & & & $\begin{array}{l}\text { Identidad con G-S.T de } \\
\text { Drosophila, muestra afinidad } \\
\text { por el glutatión }\end{array}$ & 42 \\
\hline & Der $\mathrm{p} 8$ & D. pteronyssinus & $40 \%$ & 26 & 6,3 & No & No & 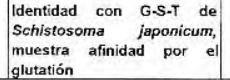 & 90 \\
\hline
\end{tabular}

de cisteína-proteasa como la papaína de la papaya (Carica papaya) y la bromelaína extraida de la piña (Ananas comosus) se les han demostrado propiedades alergénicas [2-5]. Al Der p 1 también se le ha sugerido alguna función digestiva debido a su localización en la región gastrointestinal del ácaro y su concentración alta $(0,1-0,2 \mathrm{ng} /$ partícula) en la partícula fecal del ácaro $(6,7)$.

La quimodiactina es obtenida del látex de la fruta inmadura de la papaya y está compuesta por cuatro cisteína-proteasas: quimopapaína (EC 3.4.22.6), caricaína (EC 3.4.22.30), glicilendopeptidasa (EC 3.4.22.25) y papaína (EC 3.4.22.2). Un preparado farmacéutico de quimodiactina usado para el tratamiento de la ciática produce reacciones alérgicas. Las personas con dichas reacciones tienen lgE contra todas las cisteína-proteasas mencionadas, pero predominantemente contra glicil-endopeptidasa (8).
La secuencia de aminoácidos (aa) de los extremos amino y carboxiterminal de Der $p 1$ tiene identidad con otras cisteína-proteasas como la actinidina (29\%), papaína (24\%), catepsina B $(21 \%)$ y catepsina $\mathrm{H}(28 \%)$. De estas cuatro enzimas, sólo a la papaína se le ha descrito actividad alergénica. Der $\mathrm{p} 1$ también tiene los residuos que conforman el sitio activo de la superfamilia papaína (2). Tres de estos residuos, 32, 33 y 170, se encuentran en dos de sus epítopes alergénicos $B$ y en sus epítopes $T$ $(9,10)$. Este hecho probablemente explique la doble actividad (alergénica y enzimática) hallada en la papaína y en Der p 1. La estructura espacial de Der p 1 se ha modelado a partir de los datos de las estructuras cristalográficas de la papaína y la catepsina B (11). Der $p 1$ tiene una actividad enzimática mixta de cisteínaproteasa y serina-proteasa (12). Teniendo en cuenta que el modelo estructural de este alergeno sólo predice un sitio activo y que el 
gen que lo codifica es polimórfico (13), se ha sugerido que dicha actividad mixta se debe a que las isoformas reconocidas inmunológicamente como Der $\mathrm{p} 1$ pueden poseer distinta actividad enzimática (12).

Se ha observado que Der $p 1$ es capaz de causar desprendimiento de las células del epitelio de la tráquea canina en preparaciones in vitro y que también causa lesión epitelial sin citólisis en preparaciones de las vías aéreas bovinas (14), lo cual sugiere una acción específica del Der $p 1$ sobre la unión del epitelio a la membrana basal, lo que resultaría en un aumento de la permeabilidad a éste y otros alergenos. Además, por su actividad enzimática, Der $p 1$ separa al CD23 de la membrana de los linfocitos B, alterando así la regulación de la producción de $\lg E$ (15). Los anteriores hallazgos parecen apoyar la idea de que la actividad de cisteínaproteasa de Der p 1 influya también en la patogénesis del asma alérgica.

Forteza y col., usando un modelo de ovejas alérgicas a las que se les administró extracto de Ascaris suum, detectaron que la disminución en la actividad inhibidora de alfa 1-antitripsina, un inhibidor de las serina-proteasas que protege el tracto respiratorio inferior del daño provocado por la liberación de estas enzimas durante la inflamación, se acompaña de hiperreactividad de las vías aéreas y aumento en la actividad de la calicreína tisular (16). Este resultado es consistente con la disminución significativa en la actividad inhibidora de alfa 1antitripsina en el lavado broncoalveolar de asmáticos (17). Dado que estudios in vitro muestran que Der p 1 inactiva a la alfa 1 antitripsina cortando de manera específica el centro activo de esta proteína (18), queda planteada la posibilidad de que la actividad enzimática de Der $p 1$ juegue un papel en la aparición y mantenimiento de la hiperreactividad bronquial.

Para estimar la posible influencia de la actividad enzimática del alergeno Der $p 1$ en la patogénesis del asma alérgica es importante tener en cuenta las siguientes observaciones: 1) la concentración de Der p 1 usada para determinar el efecto de la actividad cisteína-proteasa sobre el epitelio bronquial bovino (14) es mayor a los niveles encontrados en lavado broncoalveolar de individuos con asma alérgica expuestos a altos niveles del alergeno (19); 2) los estudios in vitro de la actividad de Der p 1 sobre la alfa 1antitripsina se han realizado en ausencia de inhibidores de proteasas presentes normalmente en el fluido bronquial (18). En este fluido se encuentran concentraciones de cistatina $\mathrm{C}$, un inhibidor de cisteína proteasa, treinta veces mayores que la concentración de Der p 1 (20), lo cual plantea la posibilidad de que la actividad enzimática de este alergeno quede inhibida en las condiciones fisiológicas; y 3 ) se ha demostrado acción catalítica de Der p 1 sobre el CD23 (21). El CD23 sirve de receptor a la IgE para facilitar la captura y presentación del alergeno a los linfocitos $T$, aumentando así la producción de $\operatorname{lgE}(22,23)$. De esta forma, la alergenicidad de Der p 1 podría verse afectada negativamente por su propia acción catalítica.

Debido al los hallazgos que sugieren que los alergenos con actividad de proteasas tienen un potecial efecto directo sobre las barreras del epitelio bronquial (14), se ha hipotetizado que dicha actividad pudiera facilitar la presentación antigénica al favorecer el aumento de la permeabilidad de la mucosa al paso de proteínas para luego ser procesadas y presentadas por las células dendríticas a los linfocitos $T$, y que dicho efecto, por tanto, influiría en la alergenicidad propia como en la de otros alergenos sin actividad enzimática al facilitarle su acceso a las células del sistema inmunológico $(24,25)$. Sin embargo, un modelo murino de asma alérgica, inducido por la administración de ovalbúmina por vía respiratoria, desarrolló producción de $\operatorname{lgE}$ específica e hiperreactividad bronquial, indicando que no es necesaria la presencia de una enzima para facilitar la sensibilización (26). Además, en experimentos in vivo las células dendríticas del epitelio respiratorio sano de ratas pueden capturar y procesar eficientemente a la ovalbúmina (27), lo cual sugiere que no es necesario un aumento de la permeabilidad de la mucosa para que se lleve a cabo la captura de un antígeno por parte de las células dendríticas. 


\section{Serina-proteasas}

Las serina-proteasas tripsina, quimotripsina y elastasa presentes en extractos de páncreas bovino y porcino inducen alergia ocupacional en empleados de la industria farmacéutica productora de extractos de páncreas y en personas que manipulan dichos extractos (28). Otras serina-proteasas, las subtilisinas, también han sido asociadas con alergia ocupacional en la industria de detergentes (29). Los alergenos de los ácaros domésticos Der $p 3$ y Der $f 3$, tienen actividad de tripsina, los alergenos Der p 6 y Der $f 6$ tienen actividad de quimotripsina (3035) y Der p 9 degrada al colageno tipo III obtenido de la piel del becerro y tiene un $67 \%$ de identidad en la secuencia de aa con las colagenasas de los cangrejos Paralithodes camtschatica y Chionoecetes opilio (36).

Takahashi y col. demostraron la activación del sistema calicreína-cinina por una serina proteasa en el extracto alergénico de Dermatophagoides farinae (37). La activación de este sistema participa en la broncoconstricción, formación de edema, vasodilatación, secreción de moco, activación y reclutamiento de leucocitos, activación endotelial y estimulación nerviosa en el asma bronquial (38). Dado que Der $\mathrm{f} 3$ es el responsable de la actividad de serina-proteasa en el extracto alergénico de $D$. farinae, sería interesante evaluar la participación de la actividad enzimática de Der $\mathrm{f} 3$ en la patogénesis de las enfermedades alérgicas respiratorias.

La alfa-quimotripsina en concentraciones fisiológicas induce secreción de histamina dependiente de la dosis en mastocitos del peritoneo de rata; la secreción es inhibida por bloqueadores metabólicos, fármacos antialérgicos e inhibidores de serina-proteasas. También activa el metabolismo del ácido araquidónico con liberación de prostaglandina $D_{2}$. Estas acciones sólo se reprodujeron en mastocitos de otras especies, incluyendo las humanas, cuando se usaron concentraciones citotóxicas de la enzima (39). De tal manera que la definición de si esta actividad enzimática influye en el papel alergénico de los alérgenos que la poseen, amerita mayores estudios.

\section{Aspartato-proteasas}

Al alergeno de la cucaracha Bla g 2, se le ha sugerido una actividad de aspartato proteasa debido a que su secuencia de aa tiene similitud con las secuencias de la aspartato-proteasa lisosómica del mosquito Aedes aegypti $(30,8 \%)$, la catepsina D humana $(27,0 \%)$, el pepsinó-geno humano $(26,7 \%)$, la renina humana $(2,8 \%)$ y la quimosina bovina $(29,5 \%)(40)$. Debido a su localización en el intestino y proventrículo de la cucaracha, se piensa que Bla g 2 pudiera tener una función digestiva (41, 42). A la proteasa ácida de Candida albicans, también denominada aspartil-proteinasa secretada, se le han demostrado propiedades alergénicas $(43,44)$. La pepsina porcina y la renina del hongo Cryphonectira parasitica, aunque no muy caracterizadas desde el punto de vista alergénico, están asociadas a enfermedad ocupacional en la industria farmaceútica y del queso, respectivamente (45).

\section{Actividad de carbihidrasas}

La actividad enzimática sobre los carbohidratos ha sido informada en diferentes alergenos. Desde el punto de vista del sustrato atacado, se hallaron alergenos con actividad de amilasa, hialuronidasa, pectinasa y lisozima.

\section{Amilasas}

El alergeno mayor del hongo Aspergillus orizae, Asp o 2, es una a-amilasa. La actividad alergénica de esta enzima se ha detectado tanto en productos de la industria del pan como en la enzima purificada a partir del hongo (46-49). La a-amilasa y la b-amilasa del trigo y la cebada son alergenos importantes en personas vinculadas en la industria del pan. A pesar de la actividad enzimática común en Asp o 2 y las amilasas del trigo y de la cebada, estos tres alergenos tienen muy poca alergenicidad cruzada (49-51).

La actividad a-amilasa se ha detectado en extractos alergénicos de los ácaros Acarus siro, Glyciphagus destructor, Glyciphagus domesticus, Tyrophagus longior, Rizoglyphus callae, Dermatophagoides pteronyssinus, $D$. farinae y Euroglyphus maynei (52-54). Sin embargo, so- 
lamente al alergeno purificado del extracto de D. pteronyssinus, Der $\mathrm{p} 4$, se le ha demostrado dicha actividad $(53,55)$. La identificación y caracterización de las moléculas que confieren actividad dea-amilasa en los otros extractos alergénicos está por conocerce.

\section{Hialuronidasas}

Dol $m 2$, Ves $m 2$ y Api $m 2$ son los alergenos del avispón Dolichovespula maculata, de la avispa Vespula maculifrons y de la abeja Apis mellifera, respectivamente. Se encuentran en el veneno de dichos insectos y tienen actividad de hialuronidasa. Estos alergenos tienen 25-27\% de identidad con la proteína $\mathrm{PH}-20$ del esperma del cobayo, la cual también tiene actividad hialuronidasa. Ves $v 2$ y Dol $\mathrm{m} 2$ tienen una similitud de $92 \%$ en sus secuencias de aa y poseen alergenicidad cruzada (56-58).

\section{Pectinasa y lisozimas}

Cry j 2, alergeno del polen del cedro japonés Crytomeria japonica, tiene actividad de peptinasa. La secuencia de aa de este alergeno tiene identidad con las secuencias de poligalacturonasas asociadas a la maduración del tomate $(40 \%)$ y aguacate $(43 \%)$. Sin embargo, Cry j 2 no hidroliza el ácido poligalacturónico y sólo actúa sobre el poligalacturonato metilesterificado como la pectina (59-61). Parece que la lgE específica de individuos alérgicos al cedro japonés se une al sitio activo de la enzima, lo cual es sugerido por la capacidad que tiene un anticuerpo monoclonal murino generado contra este alergeno, de inhibir tanto la actividad enzimática como la unión a la $\lg \mathrm{E}$ (62). El alergeno de la clara del huevo, Gal d 4, y el alergeno hevamina del látex de Hevea brasiliensis, son lisozimas. La heavamina tiene además, actividad de quitinasa (63-65).

\section{Fosfolipasas}

Los alergenos de la avispa, Ves $m 1$, y el avispón, Dol $m$ 1, son fosfolipasas $A_{1} B$ y el alergeno de la abeja Api $m 1$ es una fosfolipasa $A_{2}(66,67)$. Dol $m 1$ y Ves $m 1$ poseen en la región entre los aa 99 a 220 , una identidad del $31,2 \%$ con las secuencias de las triacilglicerol lipasas pancreáticas de los mamíferos. Sus se- cuencias de aa también tienen similitud con proteínas que unen calcio, aunque esta actividad no se les conoce (66). Entre la fosfolipasa $A_{2}$ de las abejas y la fosfolipasa $A_{1} B$ de las avispas existe poca similitud en sus secuencias de aa y no tienen alergenicidad cruzada (66). El sitio catalítico de Api $m 1$ es similar al de la fosfolipasa $\mathrm{A}_{2}$ de la cobra china (Naja naja atra) $(68,69)$. Sin embargo, poco se conoce sobre la capacidad alergénica de las fosfolipasas de este reptil.

La aplicación repetida de Api m 1 (0,1 $\mu \mathrm{g} / \mathrm{in}-$ yección) a ratones induce la aparición de altos títulos de IgE específica, mientras que la inyección repetida de Api m 1 cuya actividad catalítica fue eliminada mediante mutagénesis dirigida, no produce niveles detectables de IgE. Sin embargo, la aplicación de altas dosis de Api m 1 (10 $\mu \mathrm{g}$ /inyección) con o sin actividad enzimática, produce altos niveles de IgG y de $\lg E$ (67). Aunque lo anterior sugiere una participación de la actividad fosfolipasa de Api m 1, dependiendo de la dosis, en la selección de la respuesta Th-1/Th-2 y del isotipo (IgG o IgE), no se conocen hallazgos similares con las otras fosfolipasas ni en otros modelos animales.

Se conocen tres epítopes $\mathrm{T}$ en la molécula de Api m 1 (70), estudios cristalográficos indican que dos de dichos epítopes (residuos 45-62 y residuos 81-92) son importantes para la acción catalítica de la enzima debido a su ubicación alrededor del sitio de unión de la enzima con el sustrato (68).

\section{Ribonucleasas}

El alergeno de Aspergillus fumigatus, Asp f 1, tiene actividad de ribonucleasa, su secuencia de aa tiene una identidad de $99 \%$ con las secuencias de la mitogilina y la restrictocina, proteínas pertenecientes a la familia de citotoxinas que cortan el rRNA de $28 \mathrm{~S}$. Asp f 1 corta el rRNA de $28 \mathrm{~S}$ y, al igual que la mitogilina, inhibe la síntesis de proteínas (71-74).

Otro alergeno al cual se le ha demostrado actividad de ribonucleasa es el Phl p 5. Debido a la alta homología en su secuencia de aa con los alergenos Poa p 5 y Lol p $5(75,76)$ se piensa que estos dos últimos también pudieran tener 
actividad de ribonucleasa, pero, esto está por demostrarse. Phl p 5 tiene varias isoformas las cuales se agrupan en las isoformas $\mathrm{Va}$ y $\mathrm{Vb}$. Estas isoformas exhiben diferentes grados de actividad de ribonucleasa, el recombinante $\mathrm{Phl}$ p $5 \mathrm{Vb}$ tiene una actividad ribonucleasa de 830 $\mathrm{U} / \mathrm{mg}$ de proteína y constituye el $25 \%$ de la actividad ribonucleasa presente en el extracto del polen del pasto Phleum pratense. Datos experimentales sugieren que $\mathrm{Phl}$ p $5 \mathrm{Vb}$ posiblemente está relacionado con la interacción huespedpatógeno en el pasto $P$. pratense (77).

\section{Oxidorreductasas}

\section{Alcohol deshidrogenasa y aldehído deshidrogenasas}

El alergeno Cand a 1 tiene un segmento de 200 aminoácidos con un $70 \%$ de identidad con la región comprendida entre los residuos 101-310 de la isoenzima $A D H-1$ de la alcoholdeshidrogenasa de Saccharomyces cerevisiae por lo cual se le atribuye función de alcohol deshidrogenasa (78). Los alergenos Alt a 10 y Cla h 3 tienen un $80 \%$ de identidad con la secuencia de aa de la aldehído deshidrogenasa de Aspergillus fumigatus, por lo que se le ha inferido esta actividad enzimática (79), hay que señalar que el papel alergénico de la aldehidodeshidrogenasas de $A$. fumigatus no se conoce.

\section{Pectato-liasa}

El alergeno del cedro japonés Cry j 1 tiene actividad de pectato-liasa calculada en $350 \mathrm{U} / \mathrm{mg}$ de proteína (80). Su secuencia de aa tiene identidad con regiones de la pectato-liasa $A$ $(38,5 \%)$ y la pectato-liasa $E(36,7 \%)$ de la bacteria patógena para plantas Erwinia chrysanthemi (81). La actividad pectato-liasa de Cry j 1 es inhibida completamente por un antisuero de conejo contra éste, lo que sugiere que algún fragmento del sitio activo tiene inmunogenicidad (80). La secuencia de aa de Cry j 1 tiene identidad entre el 46 y $48 \%$ con la secuencia de aminoácidos de los alergenos de la maleza Ambrosia artemissifolia Amb a 1 y Amb a 2 (81). Sin embargo, no se ha demostrado que Amb a 1 y Amb a 2 tengan actividad de pectato-liasa.

\section{Enolasas}

A las enolasas de Candida albicans y $S$. cerevisiae se les ha demostrado alergenicidad (82-86). Estas dos enzimas tienen un $78,2 \%$ de identidad entre sus secuencias de aa y alergenicidad cruzada $(87,88))$. La enolasa de S. cerevisiae tiene dos isoformas a una de ellas, la enolasa-1, es la equivalente a la proteína inicialmente descrita como una proteína de choque térmico (89). El alergeno Cla h 6 tiene un $73 \%$ de identidad con la enolasa- 1 de $S$. cerevisiae por lo que se ha inferido actividad de enolasa $(79,82)$.

\section{Transferasas}

El alergeno Der $p 8$ tiene $50 \%$ de identidad con la secuencia de aa de las glutatión-Stransferasas $\mathrm{Yb}$ de rata y ratón. Tiene, además, un residuo de tirosina en la posición 8 , el cual está conservado en las glutatión-S-transferasas y parece ser importante en la unión al glutatión reducido. Se ha demostrado que Der $\mathrm{p} 8$ tiene afinidad por el glutatión reducido (90). Bla g 5 tiene un $50 \%$ de identidad con la secuencia de aa de glutatión $\mathrm{S}$ transferasa de la mosca Drosophila melanogaster (42). No se ha mostrado que la actividad glutatión-S-transferasa influya en la aparición de la atopia; sin embargo, vale mencionar que la leucotrieno $\mathrm{C}_{4}$ sintetasa, un tipo de glutatión-S-transferasa que se encuentra en la membrana celular, sintetiza uno de los mediadores más importantes en las reacciones alérgicas como es el leucotrieno $\mathrm{C}_{4}$. Esta actividad parece ser exclusiva de la leucotrieno $\mathrm{C}_{4}$ sintetasa (91).

\section{Alergenos y actividad inhibidora de enzimas}

Algunos alergenos hallados en semillas y polenes de plantas son inhibidores de la actividad de enzimas como la tripsina, a-amilasa y cisteína-proteasa. Estos alergenos pertenecen a familias de inhibidores de tripsina como las napinas, serpina e inhibidor de tripsina tipo kunitz, como también al inhibidor de cisteínaproteasa cistatina. Las principales características de estos alergenos se señalan en el cuadro 2.

\section{Inhibidores de tripsina}

Sin a 1, Bra j 1 y Ric c 1 son los alergenos de Sinapis alba (mostaza amarilla), Brassica 
Cuadro 2. Alergenos e inhibición de la actividad enzimática.

\begin{tabular}{|c|c|c|c|c|c|c|c|c|c|}
\hline FUNCION & ALERGENO & FUENTE & $\begin{array}{c}\text { FRECUENCIA } \\
\text { DE REACTIVIDAD } \\
\end{array}$ & $\begin{array}{l}\text { P.M. } \\
\text { (kDa) }\end{array}$ & $\mathrm{pl}$ & \begin{tabular}{c|} 
SITIOS DE \\
GLICOSILACION
\end{tabular} & \begin{tabular}{|c|} 
ENLACES \\
DISULFURO \\
\end{tabular} & $\begin{array}{c}\text { ACTIVIDAD } \\
\text { ASIGNADA POR }\end{array}$ & REFERENCIAS \\
\hline $\begin{array}{l}\text { INHIBICION } \\
\text { DE TRIPSINA } \\
\text { (NAPINAS) }\end{array}$ & $\begin{array}{l}\text { Sin a } 1 \\
\text { Braj } 1 \\
\text { Ric c } 1\end{array}$ & $\begin{array}{c}\text { Sinapis alba } \\
\text { Brassica juncea } \\
\text { Riccinus communis }\end{array}$ & - & $\begin{array}{l}14 \\
14 \\
14\end{array}$ & $\begin{array}{l}12,5 / 10,4 \\
12,2 / 10,0 \\
11,1 / 7,0\end{array}$ & $\begin{array}{l}\text { No } \\
\text { No } \\
\text { No }\end{array}$ & $\begin{array}{l}\text { Si (4) } \\
\text { Si (4) } \\
\text { Si (4) }\end{array}$ & \begin{tabular}{|l} 
| dentidad con \\
napinas del \\
Brassica napus
\end{tabular} & $\begin{array}{l}92 \\
94 \\
97\end{array}$ \\
\hline INHIBICION & - & Hordreum vulgare & - & $12,0-15,0$ & $4,8-6,6$ & Si (1) & $\mathrm{SI}(5)$ & Actividad Inhibidora & 103 \\
\hline $\begin{array}{l}\text { DE } \alpha \text {-AMILASA } \\
\text { Y TRIPSINA }\end{array}$ & Orys 1 & $\begin{array}{c}\text { Triticum turgidum } \\
\text { Oryza sativa }\end{array}$ & - & $\begin{array}{c}12,0-15,0 \\
16\end{array}$ & $4,8-6,6$ & si (1) & $\begin{array}{l}\text { Si (5) } \\
\text { Si (5) }\end{array}$ & $\begin{array}{l}\text { Actividad inhibidora } \\
\text { Actividad inhibidora }\end{array}$ & $\begin{array}{c}102,103 \\
104\end{array}$ \\
\hline $\begin{array}{l}\text { INHIBICION } \\
\text { DE TRIPSINA } \\
\text { TIPO KUNITZ }\end{array}$ & - & Glycine max & - & 20 & 4,5 & No & & Actividad inhibidora & 45,100 \\
\hline $\begin{array}{l}\text { INHIBICION } \\
\text { DE TRIPSINA } \\
\text { (SERPINAS) }\end{array}$ & $\begin{array}{l}\text { Gal d 1 } \\
\text { Gal d 2 }\end{array}$ & $\begin{array}{l}\text { Gallus domesticus } \\
\text { Gallus domesticus }\end{array}$ & $\begin{array}{l}34 \% \\
32 \%\end{array}$ & $\begin{array}{c}27-28 \\
45\end{array}$ & $\begin{array}{l}4,6 \\
5,0\end{array}$ & $\begin{array}{l}\text { si } \\
\text { si }\end{array}$ & & $\begin{array}{l}\text { Actividad inhibidora } \\
\text { Identldad con } \\
\text { serpinas }\end{array}$ & $\begin{array}{c}64 \\
64,98\end{array}$ \\
\hline $\begin{array}{l}\text { INHIBICION DE } \\
\text { CISTEINA- } \\
\text { PROTEASAS }\end{array}$ & $\begin{array}{c}\text { Homólogo a } \\
\text { Cistatina }\end{array}$ & A. artemisififolia & $30 \%$ & 10 & 5,0 & No & & Actividad inhibidora & 105 \\
\hline
\end{tabular}

juncea (mostaza oriental) y Ricinus communis, respectivamente. Son heterodímeros que pertenecen a la familia de proteínas de almacenamiento llamadas napinas (92-94). Debido a la alta homología de estos tres alergenos con napinas de conocida actividad inhibidora de tripsina, se les ha inferido dicha actividad y se cree que están relacionados con los inhibidores de tripsina encontrados en el trigo y la cebada (94-97).

Gal d 1 es la glicoproteína ovomucoide de la clara del huevo y un inhibidor de tripsina de la familia serpina (64). Gal d 2 es la ovoalbúmina; es estructuralmente una serpina por lo que se le ha asociado con la actividad inhibidora de tripsina pero carece de ésta debido a que adopta una conformación incompatible con dicha actividad $(64,98)$. Se han descrito alergenos de 20,0-24,0 kDa en las malezas Parietaria judaica y Ambrosia eliator, los cuales tienen actividad inhibidora de tripsina de la familia serpinas (99). En la semilla de la soya (Glycine max) se ha caracterizado un alergeno con actividad inhibidora de tripsina tipo Kunitz (45)p; el alergeno Lol p 11 está relacionado estructuralmente con este inhibidor de tripsina pero no presenta su sitio activo (100).

\section{Inhibidores de $\alpha$-amilasa y tripsina}

En las semillas del trigo y de la cebada existen alergenos con actividad de inhibidores de $\alpha$ amilasas heterólogas y de tripsina (101-103). Las distintas subunidades que constituyen las formas moleculares de los inhibidores de $\alpha$ amilasas del trigo poseen diferentes grados de alergenicidad. La forma glicosilada de una de las subunidades del trigo y la cebada son las más alergénicas. Este hallazgo sugiere la participación de los oligosacáridos como posibles epítopes B en estas proteínas (103). Ory s 1 es un alergeno que tiene un $40 \%$ identidad en su secuencia de aa con el inhibidor de $\alpha$-amilasas del trigo y $20 \%$ con el inhibidor de tripsina de la cebada (104).

\section{Cistatina}

En el polen de la malesa Ambrosia artemisiifolia, existe un alergeno homólogo con el inhibidor de cisteína-proteasa cistatina (105).

\section{Alergenos y función transportadora}

Datos experimentales y de homología en las estructuras moleculares indican que algunos alergenos pertenecen a las hemoglobinas, la citocromo $\mathrm{C}$, lipocalinas o proteínas que se 
unen a los ácidos grasos. Todas estas moléculas son de reconocida función biológica involucrada en el transporte de diferentes moléculas y elementos (cuadro 3 ).

\section{Hemoglobinas}

El mosquito Chironomus thummi thummi tiene 12 hemoglobinas homólogas; todas ellas tienen actividad alergénica y han sido designadas, según la nomenclatura de alergenos de la O.M.S., como Chi t 1. El componente III de estas hemoglobinas tiene una estructura tridimensional muy similar a la mioglobina y tiene un $16 \%$ de identidad con la secuencia de aa de la cadena $\beta$ de la hemoglobina (106-108). La mayoría de los epítopes B alergénicos en el componente III son secuenciales, uno de ellos comprende los aa 91-101 y contiene residuos involucrados en contactos con el grupo hemo (109).

\section{Citocromo C}

El alergeno del polen de la maleza Amb a $10 \mathrm{y}$ los alergenos de los pólenes de los pastos Lol $p$ 10 , Poa $p 10$ y Cyn $d 10$ pertenecen a la familia de proteínas transportadoras de la citocromo $\mathrm{C}$ (110-113).

\section{Homólogo a la estelacianina}

$\mathrm{Al}$ alergeno Amb a 3 se le ha asociado con una posible actividad transportadora debido a que es homólogo a la estelacianina, un transportador de electrones que tiene un ión metálico de cobre $(45,114)$.

\section{Transportadores de lípidos y ácidos grasos}

La función de transporte de moléculas como lípidos, ácidos grasos y retinol ha sido encontrada o inferida en diferentes alergenos. Las lipocalinas participan en el transporte y diseminación de feromonas, el transporte de pequeñas moléculas hidrofóbicas (por ejemplo, retinol), la modulación de la homeostasis celular y la síntesis enzimática (115). Los alergenos de mamíferos Bos d 1, Mus m 1, Rat $n 1$ y Rat $n 2$ y $\beta$-lactoglobulina, y el alergeno de la cucaraha Bla g 4 pertenecen a la familia de las lipolcalinas.

Bos d 1 tiene un $28 \%$ de identidad en la secuencia de aa con el alergeno Rat $n$ 2; posee además, el motivo $\mathrm{N}$-terminal común a todas las calicinas, superfamilia de proteínas transportadoras a las que pertenecen las lipocalinas (116,

Cuadro 3. Alergenos y función trasportadora

\begin{tabular}{|c|c|c|c|c|c|c|c|c|c|}
\hline FUNCION & ALERGENO & FUENTE & $\begin{array}{c}\text { FRECUENCIA } \\
\text { DE REACTIVIDAD } \\
\end{array}$ & $\begin{array}{l}\text { P.M. } \\
\text { (kDa) }\end{array}$ & $\mathrm{pl}$ & $\begin{array}{c}\text { SITIOS DE } \\
\text { GLICOSILACION } \\
\end{array}$ & $\begin{array}{c}\text { ENLACES } \\
\text { DISULFURO }\end{array}$ & $\begin{array}{c}\text { ACTIVIDAD } \\
\text { ASIGNADA POR }\end{array}$ & REFERENCIAS \\
\hline HEMOGLOBINA & Chi t 1 & Chironomus thummi & $20 \%$ & $16-32$ & 6,5 & No & No & Cristalografía & 106,108 \\
\hline CITOCROMO C & $\begin{array}{l}\text { Poa p } 10 \\
\text { Cyn d } 10 \\
\text { Lol p } 10 \\
\text { Amb a } 10\end{array}$ & $\begin{array}{l}\text { Poa pratense } \\
\text { Cynodon daction } \\
\text { Lolium perenne } \\
\text { A. artemisiifolia }\end{array}$ & - & $\begin{array}{l}12 \\
12\end{array}$ & 9,9 & & & $\begin{array}{l}\text { Determinado por } \\
\text { espectro de } \\
\text { absorción }\end{array}$ & $\begin{array}{c}111 \\
45 \\
110 \\
45\end{array}$ \\
\hline $\begin{array}{l}\text { TRANSPORTE DE } \\
\text { ELECTRONES }\end{array}$ & Amb a 3 & A. artemisiifolia & $51 \%$ & 11 & 5,5 & Si (2) & Sí (1) & $\begin{array}{l}\text { Identidad con } \\
\text { estelacianina }\end{array}$ & 114 \\
\hline $\begin{array}{l}\text { TRANSPORTE DE } \\
\text { LIPIDOS Y ACIDOS } \\
\text { GRASOS }\end{array}$ & $\begin{array}{l}\text { Mus m } 1 \\
\text { Ratn } 1 \\
\text { Rat n } 2 \\
\text { Bla g } 4 \\
\text { B-LGB } \\
\text { Bosd 1 } \\
\text { Bt 6 } \\
\text { Asc s } 1 \\
\text { Hev b } 1 \\
\text { Can f } 3\end{array}$ & $\begin{array}{c}\text { Mus musculus } \\
\text { Rattus novegicus } \\
\text { Rattus novegicus } \\
\text { Blatella germanica } \\
\text { Bos domesticus } \\
\text { Bos domesticus } \\
\text { Blomia tropicalis } \\
\text { Ascaris suum } \\
\text { Hevea brasiliensis } \\
\text { Canis familiaris }\end{array}$ & $\begin{array}{c}60 \% \\
90 \% \\
40-60 \% \\
\\
\\
\\
97 \% \\
11 \%\end{array}$ & $\begin{array}{c}19 \\
21 \\
17 \\
21 \\
\\
\\
18 \\
19,5 \\
14,8 \\
\\
14 \\
14,6 \\
\end{array}$ & $\begin{array}{c}4,7 \\
4,5 \\
4,5-5,3\end{array}$ & $\begin{array}{l}\text { No } \\
\text { No } \\
\text { Si (1) } \\
\text { No } \\
\text { No } \\
\text { No } \\
\\
\text { No } \\
\text { No }\end{array}$ & $\begin{array}{l}\text { No } \\
\text { No } \\
\text { Sí }\end{array}$ & $\begin{array}{l}\text { Cristalografia } \\
\text { Identidad con Rat n } 2 \\
\text { Cristalografia } \\
\text { Modelo a partir de } \\
\text { Mus m } 1 \\
\text { Cristalografía } \\
\text { Identidad con calicina } \\
\text { Identidad con FABP- } \\
\text { citoplásmicas } \\
\text { Experimental, RMN } \\
\text { Experimental } \\
\text { Identidad con albú- } \\
\text { minas de mamiferos }\end{array}$ & $\begin{array}{c}119,120 \\
120,121 \\
120,121 \\
122 \\
\\
123 \\
117 \\
124 \\
\\
125-127 \\
129-131 \\
132\end{array}$ \\
\hline
\end{tabular}


117). Mus $m 1$ también es conocido como proteína urinaria mayor del ratón (MUP). Se sospecha que Mus $\mathrm{m} 1$, Rat $\mathrm{n} 1$ y Rat $\mathrm{n} 2$ son lipocalinas involucradas en el transporte $y$ diseminación de feromonas debido a su presencia en la orina del animal macho y por su estructura tridimensional característica de las lipocalinas. Además, la orina de la rata macho afecta el comportamiento y respuesta sexual de las ratas hembras (118-121).

El alergeno Bla g 4 ha sido recientemente clasificado como una lipocalina ya que su secuencia de aa tiene entre 18,9 y $23,9 \%$ de identidad con las secuencias de otras lipocalinas; su secuencia de aa tiene los tres motivos característicos de las lipocalinas y un modelo de su estructura molecular predice que adopta la conformación tridimensional de las lipocalinas (122). Un alergeno importante en la leche de la vaca es la $\beta$-lactoglobulina, una lipocalina cuya función primaria parece ser el transporte de retinol. Mediante el mapeo de sus epítopes, se detectó que la secuencia TDYKKYLLFCME es un epítope inmunodominante, el cual contiene uno de los motivos característico de las lipocalinas, el TDY $(115,123)$.

En el ácaro Blomia tropicalis se ha caracterizado un alergeno denominado Bt6 que tiene homología con proteínas citoplásmicas que se une a ácidos grasos (FABP) en vertebrados e invertebrados. La secuencia de aa de Bt6 tiene un $42 \%$ de identidad con la secuencia de Sm14, una proteína que une ácidos grasos en Schistosoma mansoni y $35,3 \%$ de identidad con FABP de la vaca, rata, ratón y humana (124). Resultados preliminares de nuestro grupo de investigación, muestran que este alergeno tiene una estructura secundaria tipo $\beta$ característica de las FABP y que se une a ácidos grasos como el ácido cis-parinárico. El alergeno Asc s 1 de Ascaris suum, conocido inicialmente como ABA-1, tiene alta afinidad por ácidos grasos, retinol y ácido retinoico (125-128).

En el latex del árbol del caucho, Hevea brasiliensis, se produce el alergeno Hev b 1 que parece ser el factor elongante del caucho
(REF) (129). El REF actúa probablemente en la elongación del caucho uniendo y posicionando la preniltransfersa en la molécula del caucho $(130,131)$. El alergeno Can $\mathrm{f} 3$ es la albúmina del perro y tiene una identidad promedio de $70 \%$ con albúminas de otros mamíferos, por lo que se piensa que pudiera ejercer una función transportadora de moléculas hidrofóbicas (132).

\section{Alergenos y función de proteínas reguladoras}

Varios alergenos pertenecen a familias de proteínas reguladoras o presentan homologías con algunas de éstas, de allí que probablemente ejercen dichas funciones en su fuente de origen. Las características de estos alergenos se muestran en el cuadro 4.

\section{Alergenos que se unen a la actina}

El alergeno Bet $v 2$ del polen del árbol del abedul (Betula verrucosa) es una profilina que es funcionalmente equivalente a la profilina de los animales y participa en la estabilidad y propiedades cinéticas de los filamentos de actina $(133,134)$. Las profilinas del pasto Phleum pratense y de la maleza Artemisia vulgaris tienen propiedades alergénicas $(135,136)$. Entre Bet $v 2$ y las profilinas derivadas de alimentos y frutas existe alergenicidad cruzada, lo cual puede explicar en parte las reacciones de hipersensibilidad a alimentos que exhiben algunos individuos alérgicos al abedul (137). La profilina humana es capaz de liberar histamina de basófilos de individuos alérgicos a la profilina del abedul, lo cual sugiere que la profilina humana puede comportarse como un autoalergeno (138-140).

Los alergenos Met e 1, Pen a 1 y Pen i 1 de los camarones (Metapenaeus ensi, Penaeus aztecus, Penaeus indicus), Tod $\mathrm{p} 1$ del calamar (Todarodes pacificus) y el Der f 10 del ácaro $D$. farinae son tropomiosinas y como tal probablemente participan en la regulación de la interacción de la actina con la miosina en sus respectivas fuentes (141-144). La IgE de los individuos sensibilizados a la tropomiosina de los camarones reacciona de manera cruzada con las tropomiosinas de las otras fuentes, lo cual 
Cuadro 4. Alergenos de función de proteinas reguladoras.

\begin{tabular}{|c|c|c|c|c|c|c|c|c|c|}
\hline FUNCION & ALERGENO & FUENTE & \begin{tabular}{|c|} 
FRECUENCIA \\
DE REACTIVIDAD \\
\end{tabular} & $\begin{array}{l}\text { P.M. } \\
\text { (kDa) }\end{array}$ & $\mathrm{pl}$ & \begin{tabular}{|c|} 
SITIOS DE \\
GLICOSILACION \\
\end{tabular} & \begin{tabular}{|c|} 
ENLACES \\
DISULFURO \\
\end{tabular} & $\begin{array}{c}\text { ACTIVIDAD } \\
\text { ASIGNADA POR }\end{array}$ & REFERENCIAS \\
\hline UNION A ACTINA & $\begin{array}{l}\text { Bet v } 2 \\
\text { Phl p } 11 \\
\text { Met e 1 } \\
\text { Pen a } 1 \\
\text { Pen i } 1 \\
\text { Tod p } 1 \\
\text { Der f } 10\end{array}$ & \begin{tabular}{|c|} 
Betula verrucosa \\
Phleum pratense \\
\\
Metapenaeus ensi \\
Penaeus aztecus \\
Penaeus indicus \\
Todarodes pacificus \\
D. farinae
\end{tabular} & $\begin{array}{c}10-20 \% \\
20-30 \% \\
\\
100 \% \\
86 \% \\
70-100 \% \\
80,6 \%\end{array}$ & $\begin{array}{c}13-14 \\
14 \\
\\
34 \\
36 \\
34 \\
38 \\
37\end{array}$ & $\begin{array}{c}4,9 \\
\\
\\
5,2 \\
4,8-5,4 \\
5,1-5,9\end{array}$ & $\begin{array}{l}\text { No } \\
\text { No } \\
\text { No } \\
\text { No } \\
\text { No } \\
\text { No }\end{array}$ & $\begin{array}{l}\text { No } \\
\text { No } \\
\text { No } \\
\text { No } \\
\text { No } \\
\text { No }\end{array}$ & $\begin{array}{l}\text { Afinidad por la } \\
\text { poliprolina e } \\
\text { identidad con } \\
\text { profilinas } \\
\text { Identidad con } \\
\text { tropomiosinas y } \\
\text { comportamiento } \\
\text { tipico en SDS-PAGE }\end{array}$ & $\begin{array}{c}133,135 \\
135,136 \\
\\
141 \\
142 \\
142 \\
143 \\
144\end{array}$ \\
\hline UNION A CALCIO & Bet $v 3$ & Betula verrucosa & $10 \%$ & 23,7 & & & & $\begin{array}{l}\text { Dominios que unen } \\
\text { calcio (Mano EF) }\end{array}$ & 146 \\
\hline TROPONINA C & Blag 6 & Blatella germanica & $50 \%$ & 18 & & & & $\begin{array}{l}\text { Identidad con } \\
\text { troponina C }\end{array}$ & 42 \\
\hline $\begin{array}{l}\text { PROTEINA DE } \\
\text { CHOQUE } \\
\text { TERMICO (HSP) }\end{array}$ & $\begin{array}{l}\text { HSP-70 } \\
\text { HSP-70 } \\
\text { HSP-90 }\end{array}$ & $\begin{array}{c}\text { D. farinae } \\
\text { C. herbarum } \\
\text { Aspergillus fumigatus }\end{array}$ & $\begin{array}{c}9,8 \% \\
- \\
-\end{array}$ & 67 & & & & $\begin{array}{l}\text { Identidad con HSC-71 } \\
\text { (familia HSP-70) } \\
\text { Identidad con HSP-70 } \\
\text { Identidad con } \\
\text { HSP-90 de C. albicans } \\
\text { y S. cerevisiae }\end{array}$ & $\begin{array}{l}148 \\
149 \\
150\end{array}$ \\
\hline $\begin{array}{l}\text { FOSFOPROTEINA } \\
\text { ACIDA } \\
\text { RIBOSOMAL P2 }\end{array}$ & $\begin{array}{l}\text { Cla h } 4 \\
\text { Alt a } 6\end{array}$ & $\begin{array}{c}\text { C. herbarum } \\
\text { Alternaria alternata }\end{array}$ & $\begin{array}{l}22 \% \\
8 \%\end{array}$ & $\begin{array}{l}11 \\
11\end{array}$ & 3,94 & $\begin{array}{l}\text { No } \\
\text { No }\end{array}$ & $\begin{array}{l}\text { No } \\
\text { No }\end{array}$ & $\begin{array}{l}\text { Identidad con } \\
\text { fosfoproteinas P2 de } \\
\text { C. albicans y } \\
\text { S. cerevisiae } \\
\end{array}$ & $\begin{array}{l}79 \\
79\end{array}$ \\
\hline
\end{tabular}

explica en algunos casos la sensibilización múltiple a crustáceos, moluscos y ácaros (145). Se han identificado dos epítopes alergénicos inmunodominantes en Pen a 1 que tienen identidad en la secuencia con regiones equivalentes en las tropomiosinas de otros invertebrados como $D$. farinae y Drosofila melanogaster, el primer epítope comprende desde los residuos 50 a 66 y el segundo epítope comprende los residuos 153 a 161. Estas regiones son poco compartidas por las tropomiosinas de vertebrados, lo cual explicaría la ausencia de alergenicidad cruzada entre éstas y las tropomiosinas de los invertebrados (142).

\section{Alergenos que se unen al calcio}

Bet $\vee 3$ pertenece a una familia de proteínas que se unen al calcio y se han identificado en su molécula tres sitios de unión al calcio (146). Solo se ha detectado la expresión de mRNA de Bet $v 3$ en el polen de abedul, lo cual sugiere una función en la germinación del polen (146, 147]. Solo el alergeno unido al calcio reacciona con la IgE, lo que sugiere la presencia de epítopes conformacionales (146). El alergeno de la cucaracha Bla g 6 tiene un $70 \%$ de identidad con la secuencia de aa de otras troponinas $\mathrm{C}$, por lo que se ha sugerido que ejerce igual función que ésta en dicho insecto (42).

\section{Alergenos homólogos a las proteínas de choque térmico}

Mediante el clonaje molecular de genes y comparación de las secuencias de los alergenos codificados se identificaron dos alergenos con homología a la proteína de choque térmico de la familia 70 (HSP-70); uno, derivado del ácaro $D$. farinae, tiene un $65,5 \%$ de identidad en la secuencia de aa con la región carboxi-terminal de la proteína de choque térmico-71, de la familia HSP-70 [148] y otro derivado del hongo $C$. herbarum, el cual tiene identidad en la secuencia de aa con la región C-terminal de la HSP 70 de levadura $(71 \%)$, humano $(62 \%)$, maíz $(63 \%)$, ratón $(63 \%)$ y ganado $(67 \%)(149)$. Mediante clonaje molecular también se ha identificado un alergeno en el hongo $A$. fumigatus el cual tiene $77 \%$ de identidad en la secuencia de aa con la familia de proteínas de choque térmico HSP-90 de los hongos C. albicans y $S$. cerevisiae (150). 
Aunque la actividad HSP de los tres alergenos anteriores no se ha determinado experimentalmente, es conveniente destacar que otras proteínas de choque térmico influyen en el desarrollo de la respuesta inmune. Parece que las HSP-70 pueden unirse a péptidos de manera similar a las moléculas clase I y II del complejo mayor de histocompatibilidad; además, la estructura tridimensional del sitio de unión a los péptidos en las proteínas HSP-70 es muy parecido al sitio de unión en las moléculas HLA. Hay estudios que sugieren que algunas de la proteínas de la familia HSP-70 pudieran participar en la respuesta inmune a través de la presentación antigénica (151). También, se ha observado que las HSP pueden activar a los linfocitos T con receptor $\gamma / \delta$, los cuales hacen parte del sistema de inmunidad innata a infecciones. Además, se sospecha que algunas enfermedades auto-inmunes pueden surgir como resultado de la activación de linfocitos $\mathrm{T}$ y $\mathrm{B}$ por HSP microbianas, estos linfocitos por reactividad cruzada, reconocerían a las HSP propias (151).

\section{Alergenos homólogos a la fosfoproteína áci- da ribosomal P2}

Los alergenos de los hongos Cla h 4 y Alt a 6 son homólogos con la fosfoproteína ácida ribosomal P2 [79]. La secuencia de aa de Cla h 4 tiene identidad con proteínas ribosomales P2 de Saccharomyces cerevisiae $(61 \%)$, Schyzo- saccharomyces pombe (64\%) y Dictyostelium discoideum (56\%). También, contiene la secuencia consenso C-terminal de las proteínas ribosomales $\mathrm{P} 2$. No se ha determinado experimentalmente, si Cla h 4 puede formar complejos con las fosfoproteínas ribosomales P0 y P1 en la subunidad 60S del ribosoma, ni si regula la síntesis de proteína como se observa con las fosfoproteínas ribosomales P2 $(152,153)$.

\section{Alergenos y otras funciones biológicas}

Otras funciones biológicas sugeridas en los alergenos se muestran en el cuadro 5 . El alergeno mayor del abedul, Bet $\vee 1$, tiene varias isoformas, algunas de las cuales están codificadas por genes relacionados con la defensa o resistencia a enfermedades en plantas (154, 155). Bet $v 1$ tiene un $55 \%$ de identidad en su secuencia con el gen 149 del guisante involucrado en la resistencia a enfermedad (156). En Bet $v 1$ se ha demostrado actividad de ribonucleasa de $180 \mathrm{U} / \mathrm{mg}$ de proteína (157).

Debido a la homología de los alergenos de los polenes Cor a 1, Aln g 1 , Car b 1y Que a 1 con Bet $v 1$ se les ha sugerido también un papel en la resistencia a enfermedades (158). Un epítope alergénico $B$ inmunodominante en Bet v 1 se localiza entre los residuos 23-38 (159, 160). Se han caracterizado tres epítopes $T$ de reactividad cruzada en Bet $v 1$, Cor a 1 y Aln g

Cuadro 5. Alergenos y otras funciones biológicas.

\begin{tabular}{|c|c|c|c|c|c|c|c|c|c|}
\hline FUNCION & ALERGENO & FUENTE & $\begin{array}{c}\text { FRECUENCIA } \\
\text { DE REACTIVIDAD } \\
\end{array}$ & $\begin{array}{l}\text { P.M. } \\
\text { (kDa) }\end{array}$ & pl & \begin{tabular}{c|} 
SITIOS DE \\
GLICOSILACION
\end{tabular} & $\begin{array}{l}\text { ENLACES } \\
\text { DISULFURO } \\
\end{array}$ & $\begin{array}{c}\text { ACTIVIDAD } \\
\text { ASIGNADA POR }\end{array}$ & REFERENCIAS \\
\hline $\begin{array}{l}\text { PROTEINA DE } \\
\text { RESISTENCIA A } \\
\text { ENFERMEDAD } \\
\text { EN PLANTAS }\end{array}$ & 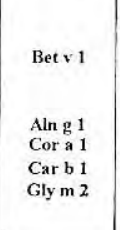 & $\begin{array}{l}\text { Betula verrucosa } \\
\text { Alnus glutinosa } \\
\text { Corylus avellana } \\
\text { Carpinus betulus } \\
\text { Glycine max }\end{array}$ & $\begin{array}{l}95 \% \\
90 \% \\
90 \% \\
90 \%\end{array}$ & $\begin{array}{l}17 \\
\\
17 \\
17 \\
17 \\
8,0\end{array}$ & $\begin{array}{l}5,2 \\
\\
5,3 \\
5,3 \\
5,8 \\
6,0\end{array}$ & No & No & $\begin{array}{l}\text { Identidad con proteina de } \\
\text { resistencia del } P \text {. sativum. } \\
\text { La producción de una iso- } \\
\text { forma aumenta en infección } \\
\\
\text { Identidad con Bet } v 1 \\
\text { Identidad con Bet } v 1 \\
\text { Identidad con Bet } v 1 \\
\text { identidad con proteina de } \\
\text { resistencia del } P \text {. sativum }\end{array}$ & $\begin{array}{c}154-156,157 \\
\\
158 \\
158 \\
158 \\
162\end{array}$ \\
\hline $\begin{array}{l}\text { PROTEINA QUE } \\
\text { CONFIERE } \\
\text { SENSIBILIDAD } \\
\text { A OLIGOMICINA }\end{array}$ & - & Bos domesticus & $31 \%$ & 21 & & No & & $\begin{array}{l}\text { Identidad con la OSCP del } \\
\text { complejo ATPasa mito- } \\
\text { condrial }\end{array}$ & 163 \\
\hline $\begin{array}{l}\text { ACTIVIDAD } \\
\text { CITOLITICA } \\
\text { (MELITINA) }\end{array}$ & Api $m 4$ & Apis mellifera & - & 2,8 & & No & No & Experimental & 164 \\
\hline
\end{tabular}


1 (161). Recientemente se secuenció el alergeno de la soya Gly m 2. El extremo N-terminal de este alergeno tiene un $64 \%$ de identidad con una proteína de resistencia a enfermedad en la arveja Pisum sativum, sugiriéndose que pudiera desempeñar esta función biológica en la soya (162).

La proteína que confiere sensibilidad a la oligomicina (OSCP, Oligomycine SensivityConferring Protein) hace parte del complejo enzimático ATP sintetasa necesario para la síntesis del ATP. Esta proteína ha sido identificada como un alergeno presente en el epitelio de la vaca, aunque su función biológica se desconoce (163).

El alergeno Api m 4, también es conocido como melitina; tiene actividad citolítica ya que polimeriza en tetrámeros que producen choque osmótico en la célula. Su alergenicidad depende de la formación del tetrámero según indica el hecho de que ratones tratados con moléculas incapaces de formar oligómeros no produjeron respuesta humoral (164).

\section{Conclusión}

Se identificaron 88 alergenos en los que se han demostrado experimentalmente o sugerido alguna función biológica basado en la identidad o similitud con otras proteínas con funciones conocidas. Se halló una gama amplia y variada de actividades bioquímica siendo la actividad enzimática la más común entre esos alergenos. Se ha planteado la hipótesis de que la actividad de cisteína-proteasa y serina-proteasa presentes en algunos alergenos de los ácaros domésticos como Der p 1, Der f 1, Der p 3, Der f 3, Der $p 6$ y Der $f 6$ pudieran tener un papel directo en la producción de IgE y la manifestación de las alergias; sin embargo, mayores estudios son necesarios para poder definirla. Aunque la homología con proteínas de función conocida ha permitido sugerir actividades bioquímicas en varios alergenos, en muchos de éstos los experimentos que demuestren la función biológica no se han realizado.

Aproximadamente $96 \%$ de los alergenos revisados tienen un peso molecular inferior a 60,0
$\mathrm{kDa}, 80 \%$ tienen un $\mathrm{pl}$ menor de 7,0 y la formación de oligómeros no es muy frecuente, aunque Asp f 1, Asc s 1, los inhibidores de $\alpha$ amilasa y tripsina, Chi $t 1$, Heb $\vee 1$, profilina, lipocalinas y Api $m 4$ pueden formar oligómeros. A nueve alergenos se les ha determinado los epítopes alergénicos $B$. Solo tres de estos alergenos, Der $p 1$, Cry j 1 y Cry j 2 , contienen algunos de estos epítopes en el sitio activo de la molécula. En siete alergenos se conocen epítopes $T$ los cuales están distribuidos a lo largo de la secuencia de aa, haciendo parte de los sitios activos e inactivos de la molécula.

\section{Referencias}

1. World Health Organization/IUIS Allergen Nomenclature Subcommittee: King TP, Hoffman D, Lowenstein H, Marsh DG, Platts-Mills TAE, Thomas W. Allergen nomenclature. J Allergy Clin Immunol 1995;96:5-14.

2. Chua KY, Stewart GA, Thomas WR, Simpson RJ, Dilworth RJ, Pozza TM, et al. Sequence analysis of cDNA coding for a major house dust mite allergen, Der p I. Homology with cysteine proteases. J Exp Med 1988;167:175-82.

3. Dilworth RJ, Chua KY, Thomas WR. Sequence analysis of cDNA coding for a major house dust mite allergen, Der $f$ I. Clin Exp Allergy 1991;21:25-32.

4. Kent NA, Hill MR, Keen JN, Holland PW, Hart BJ. Molecular characterization of group I allergen Eur $\mathrm{m}$ I from house dust mite Euroglyphus maynei. Int Arch Allergy Immunol 1992;99:150-2.

5. Platts-Mills TAE, Chapman MD. Dust mites: Immunology, allergy diseases and environmental control. J Allergy Clin Immunol 1987;80:755-65.

6. Thomas B, Heap P, Caswell F. Ultrastructural localization of the allergen Der p I in the gut of the house dust mite Dermatophagoides pteronyssinus. Int Arch Allergy Appl Immunol 1991;94:365-7.

7. Tovey ER, Chapman MD, Platts-Mills TAE. Mite faeces are a major source of house dust allergens. Nature 1981;289:592-3.

8. Dando PM, Sharp SL, Buttle DJ, Barret AJ. Immunoglobulin $E$ antibodies to papaya proteinases and their relevance to chemonucleolysis. Spine 1995;20:981-5.

9. Greene WK, Thomas WR. IgE binding structures of the major house dust mite allergen Der $p$ I. Mol Immunol 1992;29:257-62. 
10. Joost van Nerven RJ, Ebner C, Yssel $\mathbf{H}$, Kapsenberg ML, Lamb JR. T-cell responses to allergens: epitope-specificity and clinical relevance. Immunology Today 1996;17:526-31.

11. Topham CM, Srinivasan N, Thorpe CJ, Overington JP, Kalsheker NA. Comparative modelling of major house dust mite allergen Der $\mathrm{p}$ I: structure validation using an extended environmental aminoacid propensity table. Protein Eng 1994;7:869-94.

12. Hewitt CRA, Horton H, Jones RM, Pritchard DI. Heterogeneous proteolytic specificity and activity of the house dust mite proteinase allergen Der $p$ I. Clin Exp Allergy 1997;27:201-7.

13. Chua KY, Kehal PK, Thomas WR. Sequence polymorphisms of cDNA clones encoding the mite allergen Der p 1. Int Arch Allergy Immunol 1993; 101:364-8.

14. Herbert CA, King CM, Ring PC, Holgate ST, Stewart GA, Thompson PJ, et al. Augmentation of permeability in the bronchial epithelium by the house dust mite allergen Der p 1. Am J Respir Cell Mol Biol 1995;12:369-78.

15. Hewitt CR, Brown AP, Hart BJ, Pritchard DI. A major house dust mite allergen disrupts the immunoglobulin $\mathrm{E}$ network by selectively cleaving CD23: innate protection by antiproteases. J Exp Med 1995; 182:1537-44.

16. Forteza R, Botvinnikova Y, Ahmed A, Cortes A, Gundel RH, Wanner A, at al. The interaction of $\mathrm{a}_{1}$ proteinase inhibitor and tissue kallicrein in controlling allergic ovine airway hyperresponsiveness. Am J Respir Crit Care Med 1996;154:36-42.

17. Christiansen SC, Zuraw BL, Proud D, Cochrane CG. Inhibition of human bronchial kallicrein in asthma. Am Rev Respir Dis 1989;139:1125-31.

18. Kalsheker NA, Deam S, Chambers L, Sreedharan $\mathrm{S}$, Brocklehurst $\mathrm{K}$, Lomas DA. The house dust mite allergen Der $p 1$ catalytically inactivates alpha 1 antitrypsin by specific reactive centre loop cleavage: a mechanism that promotes airway inflammation and asthma. Biochem Biophys Res Commun 1996;221:5961

19. Ferguson P, Broide DH. Environmental and bronchoalveolar lavage Dermatophagoides pteronyssinus antigen levels in atopic asthmatics. Am J Respir Crit Care Med 1995;151:7-14.

20. Chapman HA, Reilly JJ Jr, Yee R, Grubb A. Identification of Cystatin C, a cysteine proteinase inhibitor, as a major secretory product of human alveolar macrophages in vitro. Am Rev Respir Dis 1990;141:698-705.

21. Schulz O, Laing P, Sewell HF, Shakib F. Der $p$ I, a major allergen of the house dust mite, proteolytically cleaves the low-affinity receptor for human IgE (CD23). Eur J Immunol 1995;25:3191-4.
22. Fujiwara $\mathbf{H}$, Kikutani $\mathbf{H}$, Suematsu $\mathbf{S}$. The absence of $\mathrm{lgE}$ antibody-mediated augmentation of immune responses in CD23-deficient mice. Proc Natl Acad Sci USA 1994;91:6835-9.

23. Coyle AJ, Wagner K, Bertrand C, Tsuyuki S, Bews $\mathrm{J}$, Heusser C. Central role of immunoglobulin $(\mathrm{lg}) \mathrm{E}$ in the induction of lung eosinophil infiltration and $T$ helper 2 cell cytokine production: Inhibition by a nonanaphylatogenic anti-lgE antibody. J Exp Med 1996;183:1303-10.

24. Robinson C, Kalsheker NA, Srinivasan N, King CM, Garrod DR, Thompson PJ, et al. On the potential significance of the enzymatic activity of mite allergens to immunogenicity. Clues to structure and function revealed by molecular characterization. Clin Exp Allergy 1997;27:10-21.

25. Canghey GH. Of mites and men: trypsin-like proteases in the lungs. Am. J. Respir. Cell Mol Biol 1977;16:621-8.

26. Renz H, Smith HR, Henson JE, Ray BS, Irvin CG, Gelfand EW. Aerosolized antigen exposure without adjuvant causes increased IgE production and increased airway responsiveness in the mouse. $J$ Allergy Clin Immunol 1992;89:1127-38.

27. Holt PG, Schon-Hegrad MA, Oliver J, Holt BJ, McMenamin PG. A contiguous network of dendritic antigen-presenting cells within the respiratory epithelium. Int Arch Allergy Appl Immunol 1990; 91:155-9.

28. Colten HR, Polakoff PL, Weinstein SF, Strieder DJ. Immediate hypersensitivity to hog trypsin resulting from industrial exposure. N Engl J Med 1975;292:1050-3.

29. Flindt MLH. Pulmonary disease due to inhalation of derivatives of Bacillus subtilis containing proteolytic enzyme. Lancet 1969;1:1177-81.

30. Smith WA, Chua KY, Kuo MC, Rogers BL, Thomas WR. Cloning and sequencing of the Dermatophagoides pteronyssinus group III allergen, Der p III. Clin Exp Allergy 1993;24:220-8.

31. Nishiyama C, Yasuhara T, Yuuki T, Okumura Y. Cloning and expression in Escherichia coli of cDNA encoding house dust mite allergen Der $f 3$, serine protease from Dermatophagoides farinae. FEBS Letters 1995;377:62-6.

32. Smith WA, Thomas WR. Comparative analysis of the genes encoding group 3 allergens from Dermatophagoides pteronyssinus and Dermatophagoides farinae. Int Arch Allergy Immunol 1996;109:133-40.

33. Stewart GA, Ward LD, Simpson RJ, Thompson PJ. The group III allergen from the house dust mite Dermatophagoides pteronyssinus is a trypsin-like enzyme. Immunology 1992;75:29-35.

34. Bennett BJ, Thomas WR. Cloning and sequencing of the group 6 allergen of Dermatophagoides pteronyssinus. Clin Exp Allergy 1996;26:1150-4. 
35. Stewart GA, Kollinger MR, King CM, Thompson PJ. A comparative study of three serine proteases from Dermatophagoides pteronyssinus and $D$. farinae. Allergy 1994;49:553-60.

36. King CM, Simpson RJ,Moritz RL, Reed GE, Thompson PJ, Stewart GA. The isolation and characterization of a novel collagenolytic serine protease allergen (Der p 9) from the dust mite, Dermatophagoides pteronyssinus. J Allergy Clin Immunol 1996;98:739-47.

37. Takahashi K, Aoki T, Kohmoto S. Activation of kallikrein-kinin system in human plasma with purified serine protease from Dermatophagoides farinae. Int Arch Allergy Appl Immunol 1990;91:80-5.

38. Bochner BS, Undem BJ, Lichtenstein LM. Immunological aspects of allergic asthma. Annu Rev Immunol 1994;12:295-335.

39. Emadi KB, Pearce FL. Some studies on the effects of alpha-chymotrypsin on mast cells from the rat and other species. Eur J Pharmacol 1996;295:243-52.

40. Arruda LK, Vailes LD, Mann BJShannon J, Fox JW, Vedvick TS, et al. Molecular cloning of major cockroach (Blatella germanica) allergen Bla g 2 . Sequence homology to the aspartic proteins. J Biol Chem 1995;270:19563-8.

41. Zwick H, Popp W, Sertl K, Rouscher H, Wanke T. Allergenic structures in cockroach hypersensitivity. J Allergy Clin Immunol 1991;89:626-30.

42. Arruda LK, Vailes LD, Benjamin DC, Chapman MD. Molecular cloning of German cockroach (Blatella germanica) allergens. Int Arch Allergy Immunol 1995;107:295-7.

43. Akiyama K, Shida T, Yasueda H, Mita H, Yamamoto T, Yamaguchi $\mathrm{H}$. Atopic asthma caused by Candida albicans acid protease: case reports. Allergy 1994;49:778-81.

44. Akiyama K, Shida T, Yasueda H, Mita H, Yanagihara $\mathbf{Y}$, Hasegawa $\mathbf{M}$, et al. Allergenicity of acid protease secreted by Candida albicans. Allergy 1996;51:887-92.

45. Stewart GA, Thompson PJ. The biochemistry of common allergens. Clin Exp Allergy 1996;26:1020-44.

46. Baur $\mathbf{X}$, Chen Z, Sander I. Isolation and denomination of an important allergen in baking additives: alphaamylase from Aspergillus oryzae (Asp o II). Clin Exp Allergy 1994;24:465-70.

47. Randez-Gil F, Sanz P. Expression of Aspergillus oryzae alpha-amylase gene in Saccharomyces cerevisiae. FEMS Microbiol Lett 1993;112:119-23.

48. Quirce S, Cuevas M, Diez-Gómez ML, et al. Respiratory allergy to Aspergillus- derived enzymes in bakers' asthma. J Allergy Clin Immunol 1992;90:970-8.
49. De Zotti R, Larese F, Molinari S. Alpha-amylase as an occupational allergen in baking industry employee. Med Lav 1994;85:142-8.

50. Sandiford CP, Tee RD, Taylor AJ. The role of cereal and fungal amylases in cereal fluor hypersensitivity. Clin Exp Allergy 1994;24:549-57.

51. Moneo I, Alday E, González-Muñoz M, Maqueda J, Curiel G, Lucena R. Alpha-amylase hypersensitivity in non-exposed millers. Occup Med Oxf 1994;44:91-4.

52. Stewart GA, Bird CH, Krska KD, Colloff MJ, Thompson PJ. A comparative study of allergenic and potentially allergenic enzymes from Dermatophagoides pteronyssinus, $D$. farinae and Euroglyphus maynei. Exp Appl Acarol 1992;16165-80.

53. Lake FR, Ward LD, Simpson RJ, Thompson PJ, Stewart GA. House dust mite-derived amylase: Allergenicity and physicochemical characterization. J Allergy Clin Immunol 1991;87:1035-42.

54. Bowman CE, Childs M. Polysaccharidases in astigmatid mites (Artrhopoda: acari). Comp Biochem Physiol 1982;72B:551-7.

55. Lake FR, Ward LD, Simpson RJ, Thompson PJ, Stewart GA. Allergenicity and physicochemical characterization of house dust mite derived amylase. Int Arch Allergy Appl Immunol 1991;94:357-8.

56. Lu G, Kochoumian L, King TP. Sequence identity and antigenic cross-reactivity of white face hornet venom allergen, also a hyaluronidase, with other proteins. J Biol Chem 1995;270:4457-65.

57. Gmachl M, Kreil G. Bee venom hyaluronidase is homologous to a membrane protein of mammalian sperm. Proc Natl Acad Sci USA 1993;90:3569-73.

58. King TP, Lu G, Gonzalez M, Qian N, Soldatova L. Yellow jacket venom allergens, hyaluronidase and phospholipase: sequence similarity and antigenic cross-reactivity with their hormet and wasp homologs and possible implications for clinical allergy. J Allergy Clin Immunol 1996;98:588-600.

59. Ohtsuki T, Taniguchi Y, Kohno K, Fukuda S, Usui M, Kurimoto M. Cry j 2, a major allergen of Japanese cedar pollen, shows polymethylgalactur-onase activity. Allergy 1995;50:483-8.

60. Namba M, Kurose M, Torigoe $\mathbf{K}$ et al. Molecular cloning of the second major allergen, Cry $j \mathrm{II}$, from Japanese cedar pollen. FEBS letters 1994;353:124-8.

61. Komiyama N, Sone T, Shimizu K, Morikubo K, Kino K. cDNA cloning and expression of Cry $j \|$, the second major allergen of japanese cedar pollen. Biochem Biophys Res Commun 1994;201:1021-8.

62. Taniai $\mathbf{M}$, Kayano $\mathbf{T}$, Takakura $\mathbf{R}$ et al. Epitopes on Cry $j I$ and $C r y j l l$ for the human IgE antibodies crossreactive between Cupressus sempervirens and Cryptomeria japonica pollen. Mol Immunol 1993;30: 183-9. 
63. Dobson CM, Evans PA, Radford SE. Understanding how proteins fold: the lysozyme story so far. TIBS 1994;19:31-7.

64. Holen E, Elsayed S. Characterization of four major allergens of hen egg-white by IEF / SDS-PAGE combined with electrophoretic transfer and IgEImmunoautoradiography. Int Arch Allergy Appl Immunol 1990;91:136-41.

65. Alenius $\mathbf{H}$, Kalkkinen $\mathbf{N}$, Lukka $\mathbf{M}$ et al. Prohevein from the rubber tree (Hevea brasiliensis) is a major latex allergen. Clin Exp Allergy 1995;25:659-65.

66. Hoffman DR. Allergens in hymenoptera venom. XXVI: The complete amino acid sequences of two vespid venom phospholipases. Int Arch Allergy Immunol 1994;104:184-90.

67. Dudler T, Cantarelli D, Kolbe L, Annand R, Rhodes $\mathrm{N}, \mathrm{Gel} \mathrm{MH}$ et al. A link between catalytic activity, IgEindependent mast cell activation, and allergenicity of bee venom phospholipase $A_{2}$. J Immunol 1995; 155:2605-13.

68. Scott DL, Otwinowski Z, Gelb MH, Sigler PB. Crystal structure of bee-venom phospholipase $A_{2}$ in a complex with a transition-state analogue. Science 1990;250:1563-6.

69. Scott DL, White SP, Otwinowski Z, Yuan W, Gelb MH, Sigler P. Interfacial catalysis: the mechanism of phospholipase A . Science 1990;250:1541-6.

70. Carballido JM, Carballido-Perrig N, Kägi MK, et al. $T$ cell epitope specificity in human allergic and nonallergic subjects to bee venom phospholipase $A_{2}$. J Immunol 1993;150:3582-91.

71. Moser M, Crameri R, Menz G, Schneider T, Dudler $\mathbf{T}$, Virchow $\mathbf{C}$, et al. Cloning and expression of recombinant Aspergillus fumigatus allergen 1/a ( $r$ Asp $f$ 1/a) with $\operatorname{lgE}$ binding and type I skin test activity. J Immunol 1992;149:454-60.

72. Arruda LK, Mann BJ, Chapman MD. Selective expression of a major allergen and citotoxin, Asp $\mathrm{fl}$, in Aspergillus fumigatus. Implications for the immunopathogenesis of Aspergillus-related diseases. J Immunol 1992;149:3354-9.

73. Arruda LK, Platts-Mills TAE, Fox JW, Chapman MD. Aspergillus fumigatus allergen I, a major IgE-binding protein, is a member of the mitogillin family of cytotoxins. J Exp Med 1990;172:1529-32.

74. Sporik RB, Arruda LK, Woodfolk J, Chapman MD, Platts-Mills TAE. Environmental exposure to Aspergillus fumigatus allergen $(A s p f \mathrm{I})$. Clin Exp Allergy 1993;23:326-31.

75. Klysner S, Welinder KG, Lowenstein H, Matthiesen F. Group V allergen in grass pollens:IV. Similiraties in amino acid compositions and $\mathrm{NH} 2$-terminal sequences of group $\mathrm{V}$ allergens from Lolium perenne, Poa pratensis and Dactylis glomerata. Clin Exp Allergy 1992:22:491-7.
76. Vrtala S, Sperr WR, Reimitzer I, van Ree R, Loffer $\mathrm{S}$, Muller WD, et al. cDNA cloning of a major allergen from timothy grass (Phleum pratense) pollen; characterization of the recombinant $P h l p V$ allergen. $J$ Immunol 1993;151:4773-81.

77. Bufe A, Schramm G, Keown MB, Schlaak M, Becker W-M. Major allergen $P h l p$ Vb in timothy grass is a novel pollen RNase. FEBS Letters 1995;363:6-12.

78. Shen H-D, Choo K-B, Lee H-H, Hsieh SC, Lin WL, Lee WR et al. The 40-kilodalton allergen of Candida albicans is an alcohol dehydrogenase: molecular cloning and immunological analysis using monoclonal antibodies. Clin Exp Allergy 1991;21:675-81.

79. Achatz G, Oberkofler H, Lechenauer E, Simon B, Vnger A, Kandler D, et al. Molecular cloning of major and minor allergens of Alternaria alternata and Cladosporium herbarum. Mol Immunol 1995;32:213-27.

80. Taniguchi $\mathbf{Y}$, Ono A, Sawatani M, Namba M, Kohno $\mathbf{K}$, Usui $\mathbf{M}$ et al. Cry $j$ l, a major allergen of Japanese cedar pollen, has pectate lyase enzyme activity. Allergy 1995;:50:90-3.

81. Sone T, Komiyama N, Shimizu K, Kusakabe T, Morikubo K, Kino K. Cloning and sequencing of cDNA coding for $C r y j \mathrm{l}$, a major allergen of Japanese cedar pollen. Biochem Biophys Res Commun 1994;199: 61925.

82. Breitenbach M, Simon B, Probst G, Oberkofler H, Ferreira F, Briza $P$, et al. Enolases are highly conserved fungal allergens. Int Arch Allergy Immunol 1997;113:114-7.

83. Ito K, Ishiguro A, Kanbe T, Tanaka K, Torii S. Detection of $\operatorname{lgE}$ antibody against Candida albicans enolase and its crossreactivity to Saccharomyces cerevisiae enolase. Clin Exp Allergy 1995;25:522-8.

84. Baldo BA, Baker RS. Inhalant allergies to fungi: reactions to bakers' yeast (Saccharomyces cerevisiae) and identification of bakers' yeast enolase as an important allergen. Int Arch Allergy Appl Immunol 1988;86:201-8.

85. Savolainen J, Viander M, Koivikko A. IgE-, IgA- and IgG- antibody responses to carbohydrate and protein antigens of Candida albicans in asthmatic children. Allergy 1990;45:54-63.

86. Savolainen J, Lammintausta K, Kalimo K, Viander M. Candida albicans and atopic dermatitis. Clin Exp Allergy 1993;23:332-9.

87. Sundstrom P, Aliaga GR. Molecular cloning of cDNA and analysis of protein secondary structure of Candida albicans enolase, an abundant, immunodominant glycolytic enzyme. J Bacteriol 1992; 174:6789-99.

88. Ito $\mathrm{K}$, Ishiguro A, Kanbe $\mathrm{T}$, Tanaka $\mathrm{K}$, Torii $\mathrm{S}$. Characterization of IgE-binding epitopes on Candida albicans enolase. Clin Exp Allergy 1995;25:529-35.

89. lida $\mathrm{H}$, Yahara I. Yeast heat-shock protein of $\mathrm{Mr}$ 48000 is an isoprotein of enolase. Nature $1985 ; 315$ : 688-90. 
90. O'Neill GM, Donovan GR, Baldo BA. Cloning and characterization of a major allergen of the house dust mite, Dermatophagoides pteronyssinus, homologous with glutathione S-transferase. Biochim Biophys Acta 1994;1219:521-8.

91. Rushmore TH, Pickett CB. Glutathione Stransferases, structure, regulation, and therapeutic implications. J Biol Chem 1993;268:11475-8.

92. González de la Peña MA, Villalba M, GarcíaLópez JL, Rodríguez R. Cloning and expression of the major allergen from yellow mustard seeds, Sin a I. Biochem Biophys Res Commun 1993;190:648-53.

93. Menéndez-Arias L, Domínguez J, Moneo I, Rodríguez R. Epitope mapping of the major allergen from yellow mustard seeds, Sin a I. Mol Immunol 1990; 27:143-50.

94. Svendsen IB, Nicolova D, Goshev I, Genov N. Isolation and characterization of a trypsin inhibitor from the seeds of kohlrabi (Brassica napus var. rapifera) belonging to the napin family of storage proteins. Calsberg Res Commun 1989;54:231-9.

95. Monsalve RE, Gonzales de la Peña MA, Menendez-Arias L. Characterization of a new orientalmustard (Brassica juncea) allergen, Bra j 1 IE:Detection of an allergenic epitope. Biochem $J$ 1993;293:625-628.

96. Irwin SD, Lord JM. Nucleotide sequence of a Ricinus communis $2 \mathrm{~s}$ albumin precursor gene. Nucl Acids Res 1990;18:5890.

97. Thorpe SC, Kemeny DM, Panzani RC, McGurl B, Lord M. Allergy to castor bean. II. Identification of the major allergens in castor bean seeds. J Allergy Clin Immunol 1988;82:67-72.

98. Carrell RW, Whisstock J, Lomas DA. Conformational changes in serpins and the mechanism of á -antitrypsin deficiency. Am J Respir Crit Care Med 1994;150:S171-5.

99. Berrens L., Marañón F. IgE-binding trypsin inhibitors in plant pollen extracts. Experientia 1995; 51:953-5.

100. van Ree R, Hoffman DR, van Dijk W, Brodard V, Mahien K, Kolleman CA, et al. Lol p XI, a new major grass pollen allergen, is a member of a family of soybean trypsin inhibitor-related proteins. J Allergy Clin Immunol 1995;95:970-8.

101. James JM, Sixbey JP, Helm RM, Bannon GA, Burks AW. Wheat a-amylase inhibitor: A second route of allergic sensitization. J Allergy Clin Immunol 1997;99:239-44.

102. Gómez L, Martín E, Hernández D, Sanchéz-Monge R, Barber D, del Pozo V, et al. Members of the $\alpha$ amylase inhibitors family from wheat endosperm are major allergens associated with baker's asthma. FEBS letts 1990;261:85-8.

103.Sánchez-Monge R, Gómez L, Barber D, López-Otín C, Armentia A, Salcedo G. Wheat and barley allergens associated with baker's asthma. Glycosylated subunits of the $\alpha$-amylase inhibitor family have enhanced IgE-binding capacity. Biochem J 1992;281:40-5.

104. Izumi H, Adachi T, Fujii N. Nucleotide sequence of a cDNA clone encoding a major allergenic protein in rice seeds. Homology of the deduced amino acid sequence with members of a-amylase/trypsin inhibitor FEBS 1992;302:213-6.

105. Rogers BL, Pollock J, Klapper DG, Griffith IJ. Complete sequence of a proteinase inhibitor cystatin homologue from the pollen of Ambrosia artemisiifolia (short ragweed). Gene 1993;133: 219-21.

106. Liebers V, Baur X. Chironomidae haemoglobin Chit $t$ characterization of an important inhalant allergen. Clin Exp Allergy 1994;24:100-8.

107. Baur X, Liebers V, Mazur G, Steigemann W. Several epitope structures of Chit I component III. I. Bcell and T-cell epitopes in the crystal structure of Chit I component III. In: Kraft D., Sehon A., eds. Molecular biology and immunology of allergens. Boca Raton: CRC Press; 1993:295-6.

108. Baur X, Aschauer H, Mazur G, Dewair M, Prelicz H, Steigemann W. Structure, antigenic determinants of some clinically important insect allergens: chironomids hemoglobins. Science 1986;233:351-4.

109. Van Kampen V, Becker W-M, Chen Z et al. Analysis of B-cell epitopes in the $\mathrm{N}$-terminal region of Chi $t$ component III using monoclonal antibodies. Mol Immunol 1994;31:1133-40.

110. Ansari AA, Killoran EA, Marsh DG. An investigation of human immune response to perennial ryegrass (Lolium perenne) pollen cytochrome c (Lol p X). J Allergy Clin Immunol 1987; 80:229-35.

111. Ekramoddoullah AKM, Kisil FT, Sehon AH. Isolation of allergenically active cytochrome c from kentucky blue grass pollen. Int Archs Allergy Appl Immunol 1981;65:367-76.

112. Ekramoddoullah AKM, Kisil FT, Sehon AH. Allergenic cross-reactivity of cytochromes $c$ of kentucky blue grass and perennial ryegrass pollen. Mol Immunol 1982;19:1527-34.

113. Ekramoddoullah AKM, Kisil FT, Bundesen PG, Fisher JMM, Rector ES, Sehon AH. Determinants of rye grass pollen cytochrome $\mathrm{c}$ recognized by human $\mathrm{IgE}$ and murine monoclonal antibodies. Mol Immunol 1984;21:375-82.

114. Klapper DG, Goodfriend L, Capra JD. Amino acid sequence of ragweed allergen pollen Ra3. Biochemistry 1980;19:5729-34.

115. Flower DR, Sansom CE, Beck ME, Attwood TK. The first prokaryotic lipocalins. TIBS 1995;20:498-9.

116. Rautiainen J, Pentikäinen J, Rytkönen M, LinnalaKan k, kunen A, Pelkonen J, et al. Molecular 
analysis of allergenic proteins in bovine dander. Allergy 1996;51:378-82.

117. Mäntyjärvi $R$, Parkkinen $S$, Rytkönen $M$, Pentikainer J, Pelkonen J, Rutiairan J, et al. Complementary DNA cloning of the predominant allergen of bovine dander: a new member in the lipocalin family. J Allergy Clin Immunol 1996;97:1297303.

118. Newman Taylor A, Longbottom JL, Pepys J. Respiratory allergy to urine proteins of rats and mice. Lancet 1977;2:847-9.

119. Longbottom JL, Price JA. Allergy to laboratory animals: characterization and source of two major mouse allergens, Ag1 and Ag3. Int Arch Allergy Appl Immunol 1987;82:450-2.

120. Bocskei Z, Groom CR, Flower DR, Wright CE, Phillips SE, Caraggioni A, et al. Pheromone binding to two rodent urinary proteins revealed by $\mathrm{X}$-ray crystallography. Nature 1992;360:186-8.

121. Gordon S, Tee RD, Newman Taylor AJ. Analysis of rat urine proteins and allergens by sodium dodecyl sulfate-polyacrilamide gel electrophoresis and immunoblotting. J Allergy Clin Immunol 1993;92: 298305.

122. Arruda LK, Vailes LD, Hayden ML, Benjamin DC, Chapman MD. Cloning of cockroach allergen, Bla g 4, identifies ligand binding proteins (or calycins) as a cause of IgE antibody responses. J Biol Chem 1995; 270:31196-201.

123. Ball G, Shelton MJ, Waish BJ, Hill DJ, Hosking CS, Howden MEH. A major continuous allergenic epitope of bovine b-lactoglobulin recognized by human $\lg \mathrm{E}$ binding. Clin Exp Allergy 1994;24:758-64.

124. Caraballo L, Puerta L, Jiménez S, Asil A, Marsh D. Cloning and IgE binding of a recombinant allergen from the mite Blomia tropicalis, homologous with fatty acidbinding proteins. Int Arch Allergy Immunol 1997;112:341-7.

125. Christie JF, Dunbar B, Davidson I, Kennedy MW. Nterminal aminoacid sequence identity between a major allergen of Ascaris lumbricoides and Ascaris suum, and $\mathrm{MHC}$-restricted IgE responses to it. Immunology 1990;69:596-602.

126. Christie JF, Dunbar B, Kennedy MW. The ABA-1 allergen of the nematode Ascaris suum: epitope stability, mass spectrometry, and $\mathrm{N}$-terminal sequence comparison with its homologue in Toxocara canis. Clin Exp Immunol 1993;92:125-32.

127. Kennedy MW, Brass A, McCruden AB, Price NC, Kelly SM, Cooper A. The ABA-1 allergen of the parasitic nematode Ascaris suum: Fatty acid and retinoid binding function and structural characterization. Biochemistry 1995;34:6700-10.

128. Lee TDG, Xie CY. IgE regulation by nematodes: The body fluid of Ascaris contains a B-cell mitogen. J Allergy Clin Immunol 1995;95:1246-54.
129. Czuppon AB, Chen Z, Rennert Z, et al. The rubber elongation factor of rubber trees (Hevea brasiliensis) is the major allergen in latex. J Allergy Clin Immunol 1993;92:690-7.

130. Dennis MS, Light DR. Rubber elongation factor from Hevea brasiliensis. Identification, characterization and role in rubber biosynthesis. J Biol Chem 1989;264:18606-17.

131. Dennis MS, Henzel WJ, Bell J, Kohr W, Light D. Amino acid sequence of rubber elongation factor protein associated with rubber particles in Hevea latex. J Biol Chem 1989;264:18618-26.

132. Spitzauer S, Schweiger C, Sperr WR, Pandjaitan B, Valent R, Muhl S, et al. Molecular characterization of dog albumin as a cross-reactive allergen. J Allergy Clin Immunol 1994;93:614-27.

133. Swoboda I, Ferreira F, Vrtala S, Duchene M, Deviller $P$, Meagher $R$, et al. Occurrence and properties of profilins in plants. In: Kraft D, Sehon A, eds. Molecular biology and immunology of allergens. Boca Raton: CRC Press; 1993:169-71.

134. Rothkegel M, Mayboroda $\mathbf{O}$, Rohde $M$, Wucherpfenning $\mathbf{C}$, Valenta $\mathbf{R}$, et al. Plant and animal profilins are functionally equivalent and stabilize microfilaments in living animal cells. J Cell Science 1996;109:83-90.

135. Valenta R, Duchene M, Ebner C, Valenta P, Sillaber C, Deviller P, et al. Profilins constitute a novel family of functional plant pan-allergens. J Exp Med 1992;175:377-85.

136. Valenta R, Ball T, Vrtala S, Duchêne M, Kraft D, Scheiner O. cDNA cloning and expression of timothy grass (Phleum pratense) pollen profilin in Escherichia coli: comparison with birch pollen profilin. Biochem Biophys Res Commun 1994;199:106-18.

137. Ivan Ree $R$, Voitenko V, van Leeuwen WA, Aalberse RC. Profilin is a cross-reactive allergen in pollen and vegetable foods. Int Arch Allergy Immunol 1992;98:97-104.

138. Duchêne M, Ortner S, Wiedermann G, Kraft D, Scheiner O, Valenta R. Entamoeba histolitica profilin binds serum IgE from pollen allergic patients. In: Kraft D, Sehon A, eds. Molecular biology and immunology of allergens. Boca Raton: CRC Press; 1993:173-5.

139. Valenta R, Duchêne M, Pettenburger K, Sillaber C, Valenta P, Bettelheim R, et al. Identification of profilin as a novel pollen allergen; IgE autoreactivity in sensitized individuals. Science 1991;253:557-60.

140. Valent P, Valenta R, Sperr WR, Sillaber C, Lachner $\mathbf{K}$, Ferreira $\mathbf{F}$, et al. Endogenous human profilin fulfills criteria of an IgE dependent histamine releasing factor (HRF).In: Kraft D, Sehon A, eds. Molecular biology and immunology of allergens. Boca Raton: CRC Press; 1993:177-83.

141. Leung PSC, Chu KH, Chow WK, Ansari A, Bandes C, Kwan $\mathrm{H}$, et al. Cloning, expression, and primary 
structure of Metapenaeus ensis tropomyosin, the major heat-stable shrimp allergen. J Allergy Clin Immunol $1994 ; 94: 882-90$

142. Shanti KN, Martin BM, Nagpal S, Metcalfe DD, Subba Rao PV. Identification of tropomyosin as the major shrimp allergen and characterization of its $\operatorname{lgE}$ binding epitopes. J Immunol 1993;151:5354-63.

143. Miyazawa H, Fukamachi H, Inagaki Y, Reese G, Daul CB, Lehrer SB, et al. Identification of the first major allergen of a squid (Todarodes pacificus). $\mathrm{J}$ Allergy Clin Immunol 1996;98:948-53.

144. Aki T, Kodama T, Fujikawa A, Miura K, Shigeta S, Wada T, et al. Immunochemical characterization of recombinant and native tropomyo sins as a new allergen from the house dust mite, Dermatophagoides farinae. J Allergy Clin Immunol 1995;96:74-83.

145. Leung PSC, Chow WK, Duffey S, Kwan HS, Gershwin E, Chu KH. IgE reactivity against a crossreactive allergen in crustacea and mollusca: evidence for tropomyosin as the common allergen. J Allergy Clin Immunol 1996;98:954-61.

146. Seiberler S, Scheiner O, Kraft D, Lonsdale D, Valenta R. Characterization of a birch pollen allergen, Bet $v \mathrm{III}$, representing a novel class of $\mathrm{Ca}^{2+}$ binding proteins; specific expression in mature pollen and dependence of patients' IgE binding on protein-bound $\mathrm{Ca}^{2+}$. EMBO J 1994;13:3481-6.

147. Seiberler S, Kraft D, Scheiner O, Valenta R. Homology of two cDNAs coding for birch pollen allergens with calmodulin and calmodulin-like proteins In: Kraft D, Sehon A, editors. Molecular biology and immunology of allergens. Boca Raton: CRC Press; 1993:227-9.

148. Aki T, Fujikawa A, Wada T, Jyo T, Shigeta S, Murrooka Y, et al. Cloning and expression of cDNA coding for a new allergen from the house dust mite, Dermatophagoides farinae: homology with human heat shock cognate proteins in the heat shock protein 70 family. J Biochem 1994;115:435-40.

149. Zhan L, Muradia G, De Vouge MW, Rode H, Vijay HM, An allergenic polypeptide representing a variable region of hsp 70 cloned from a cDNA library of Cladosporium herbarum. Clin Exp Allergy 1996;26:88-95.

150. Kumar A, Reddy LV, Socahnik A, Kurup VP. Isolation and characterization of a recombinant heat shock protein of Aspergillus fumigatus. J Allergy Clin Immunol 1993;91:1024-30.

151. Welch WJ. Mammalian stress response: Cell physiology, structure / function of stress proteins, and implications for medicine and disease. Physiological Reviews 1992;72:1063-80.

152. Zhang L, Muradia G, Curran IHA, Rode H, Vijay HM. A cDNA clone coding for a novel allergen, Cla $h \mathrm{III}$, of Cladosporium herbarum identified as a ribosomal $\mathrm{P}_{2}$ protein. J Immunol 1995;154:710-7.

153. Rich B, Steitz JA. Human acidic ribosomal phosphoproteins P0, P1, and P2: Analysis of cDNA clones, in vitro synthesis, and assembly. Mol Cell Biol 1987;7:4065-74.

154. Swoboda I, Scheiner O, Kraft D, Breitenbach M, Heberle-Bors E, Vicente $O$. A birch gene family encoding pollen allergens and pathogenesis-related proteins. Biochim Biophys Acta 1994;1219:457-64.

155. Menz G, Dolecek C, Schönheit-Kenn U, Ferreira F, Moser M, Scheider T, et al. Serological and skin-test diagnosis of birch pollen allergy with recombinant Bet $v$ I, the major birch pollen allergen. Clin Exp Allergy 1996;26:50-60.

156. Breiteneder H, Pettenburger K, Bito A, Valenta R, Kraft D, Runpold M, et al. The gene coding for the major birch pollen allergen Bet $v \mathrm{I}$, is highly homologous to a pea disease resistance response gene. EMBO J 1989;8:1935-8.

157. Bufe A, Spangfort MD, Kahlert H, Schlaak M, Becker WM. The major birch pollen allergen, Bet $\vee 1$, shows ribonuclease activity. Planta 1996;199:413- 5.

158. Ipsen $\mathrm{H}$, Hansen $\mathrm{OC}$. The $\mathrm{NH}_{2}$-terminal amino acid sequence of the immunochemically partial identical major allergens of alder (Alnus glutinosa) Aln $\mathrm{gl}$, birch ( Betula verrucosa) Bet v I, hornbeam (Carpinus betulus) Car b I and oak (Quercus alba) Que a I pollens. Mol Immunol 1991;28:1279-88.

159. Elsayed S, Holen E, Dybendal T. Synthetic allergenic epitopes from the amino-terminal regions of the major allergens of hazel and birch pollen. Int Arch Allergy Appl Immunol 1989;89:410-5.

160. Vik H, Steinsvaag SK, Dybendal T, Florvaag E, Holen E, Elsayed S. Studies on the biological activities of the aminoterminal epitope 23-38 from the major birch pollen allergen Bet $v$ I.patients. In: Kraft D, Sehon A, eds. Molecular biology and immunology of allergens. Boca Raton: CRC Press; 1993:223-5.

161. Ebner C, Ferreira F, Hoffman K, Hirschwehr R, Schenk S, Szepfalusi Z, et al. T cell clones specific for Bet $v \mathrm{I}$, the major birch pollen allergen, crossreact with the major allergens of hazel, Cor a I, and alder, Aln $\mathrm{g}$ I. Mol Immunol 1993;30:1323-9.

162. Codina R, Lockey RF, Fernández-Caldas E, Rama R. Purification and characterization of a soybean hull allergen responsible for the Barcelona asthma outbreaks. II. Purification and sequencing of the Gly $m$ 2 allergen. Clin Exp Allergy 1997;27:424-30.

163. Parkkinen S, Rytkönen M, Pentikäinen J, Virtanen T, Mäntyjärvi R. Homology of a bovine allergen and the oligomycin sensitivity-conferring protein of the mitochondrial adenosine triphosphate synthase complex. J Allergy Clin Immunol 1995;95: 1255-60. 
164. King TP, Coscia MR, Kochoumian L. Structure immunogenicity relationship of a peptide allergen, mellitin. In: Kraft D, Sehon A, eds. Molecular biology and immunology of allergens. Boca Raton: CRC Press; 1993:11-9. 